University of Nebraska - Lincoln

DigitalCommons@University of Nebraska - Lincoln

Biological Systems Engineering: Papers and

Publications

Biological Systems Engineering

$1-2012$

\title{
Evaluation of the impact of surface residue cover on single and dual crop coefficient for estimating soybean actual evapotranspiration
}

\author{
Lameck O. Odhiambo \\ University of Nebraska-Lincoln, lodhiambo2@unl.edu \\ Suat Irmak \\ University of Nebraska-Lincoln, suat.irmak@unl.edu
}

Follow this and additional works at: https://digitalcommons.unl.edu/biosysengfacpub

Part of the Biological Engineering Commons

Odhiambo, Lameck O. and Irmak, Suat, "Evaluation of the impact of surface residue cover on single and dual crop coefficient for estimating soybean actual evapotranspiration" (2012). Biological Systems Engineering: Papers and Publications. 218.

https://digitalcommons.unl.edu/biosysengfacpub/218

This Article is brought to you for free and open access by the Biological Systems Engineering at DigitalCommons@University of Nebraska - Lincoln. It has been accepted for inclusion in Biological Systems Engineering: Papers and Publications by an authorized administrator of DigitalCommons@University of Nebraska Lincoln. 


\title{
Evaluation of the impact of surface residue cover on single and dual crop coefficient for estimating soybean actual evapotranspiration
}

\author{
L. O. Odhiambo and S. Irmak \\ Department of Biological Systems Engineering, University of Nebraska-Lincoln, \\ 241 L.W. Chase Hall, Lincoln, NE 68583, USA \\ Corresponding author - S. Irmak, tel 402 472-4865, fax 402 472-6338, email sirmak2@unl.edu
}

\begin{abstract}
Single and dual crop coefficient methods are used in conjunction with grass reference evapotranspiration (ET $)$ to estimate actual crop evapotranspiration $\left(E T_{c}\right)$. However, the impact of soil surface residue cover on the accuracy of $E T_{c}$ estimated with these methods is not well understood. The objective of this study is to evaluate and compare the accuracy of the FAO-56 single crop coefficient (single- $\left.K_{c}\right)$ and dual crop coefficient (dual- $\left.K_{c}\right)$ methods for estimating soybean [Glycine $\max \left(\mathrm{L}\right.$.) Merr.] $E T_{c}$ in a partially residue covered field. The study was conducted at the University of Nebraska-Lincoln, South Central Agricultural Laboratory (SCAL), Nebraska, during the 2007 and 2008 growing seasons. The field was under reduced-tillage (ridge till) on a silt loam soil and irrigated using a subsurface drip irrigation system. Evapotranspiration flux $\left(E T_{m}\right)$ above the crop canopy was measured using a deluxe version of a Bowen ratio energy balance system (BREBS) and $E T_{o}$ was calculated with the Penman-Monteith method. The single- $K_{c}$ and dual$K_{c}$-estimated $E T_{c}$ values, both unadjusted for residue cover, were compared to $E T_{m}$. The unadjusted FAO-56 $K_{c}$ values performed poorly as the single- $K_{c}$ underestimated $E T_{m}$ during the initial crop growth stage by $21 \%$ in 2007 and $33.6 \%$ in 2008 while the dual- $K_{c}$ overestimated $E T_{m}$ during the same growth stage by $16.8 \%$ in 2007 and $16.5 \%$ in 2008 . Extended simulations were conducted to determine the magnitude by which $E T_{c}$ is reduced for each $10 \%$ of soil surface covered with crop residue. Downward adjustments in soil water evaporation $\left(E_{s}\right)$ for every $10 \%$ of the soil surface covered with crop residue improved the accuracy of $E T_{c}$ estimated by the dual- $K_{c}$ method. The largest changes in $E T_{c}$ due to adjustments in $E_{s}$ occur during the initial stage of the growing season. The best estimates for seasonal $E T_{c}$ were obtained by reducing $E_{s}$ by $5 \%$ for every $10 \%$ of surface covered with residue in $2007\left(R^{2}=0.77, R M S D=0.87 \mathrm{~mm} \mathrm{~d}^{-1}\right.$, $E=0.94)$ and $2008\left(R^{2}=0.83, \mathrm{RMSD}=0.84 \mathrm{~mm} \mathrm{~d}^{-1}, E=0.95\right)$. Greater improvements in the accuracy of estimated seasonal $E T_{c}$ were obtained by reducing $E_{s}$ by $2.5 \%$ for each $10 \%$ of surface covered with residue during the initial stage and by $5 \%$ during the rest of the crop growth stage. These results suggest that the more computationally-involved dual- $K_{c}$ method with adjustments in $E_{s}$ for each $10 \%$ of surface covered with residue improves the prediction of $E T_{c}$ in fields with soil surface residue cover, especially during the initial growth stage. Inaccurate selection of percentage reduction in $E_{s}$ can result in substantial overestimation or underestimation of seasonal $E T_{c}$ by the dual- $K_{c}$ method.
\end{abstract}

Keywords: Bowen ratio, Soil water stress coefficient, Soil evaporation coefficient, Crop coefficient, Residue cover

\section{Introduction}

Crop evapotranspiration $\left(E T_{c}\right)$ from agricultural fields is the sum of crop transpiration $(T)$, soil water evaporation $\left(E_{\mathrm{s}}\right)$, and direct evaporation of rainfall intercepted by plant canopy and crop residue $\left(E_{\mathrm{i}}\right)$. $E_{\mathrm{i}}$ normally occurs for a very small period following rainfall or sprinkler irrigation and is commonly considered insignificant in many $E T_{c}$ estimation methods. Meteorological conditions determine the atmospheric evaporating power which is characterized by a grass-reference crop evapotranspiration $\left(E T_{o}\right)$. In addition to many other factors, the rate of $T$ is affected by crop growth stage and soil water content in the root zone, while the rate of $E_{\mathrm{s}}$ is influenced by different fac- tors that affect soil surface conditions such as tillage practice, crop residue cover on the soil surface, and soil surface wetness. Crop residue left on the surface apart from intercepting rainfall also insulates the soil surface from radiant and advective energy (Steiner, 1989), and increases the diffusive resistance of water vapor transport from the soil to the atmosphere (Hammel, 1996; Flury et al., 2009). Several field studies have shown that surface crop residue can reduce $E_{\mathrm{s}}$ (Russel, 1939; Moody et al., 1963; Adams, 1966; Bond and Willis, 1970; Todd et al., 1991; Heilman et al., 1992; Klocke et al., 2009). Unger and Parker (1976) compared the effects of different types of residue on $E_{\mathrm{s}}$ and found residue thickness and surface coverage, rather than residue type, to be the main factors affecting $E_{\mathrm{s}}$. Other studies 
have also shown that crop residue that only partially covers soil surface has less effect on $E_{\mathrm{s}}$ because of greater surface temperature and larger drying gradients between bare soil and soil under residue covered areas (Willis, 1962; Chung and Horton, 1987; Steiner, 1989; Klocke et al., 2009).

Accurate estimation of $E T_{c}$ in a soil-residue-crop system is of major interest for comparing crop water use between different tillage practices, determining regional irrigation water requirements, and in-season irrigation management. Direct field measurements of $E T_{c}$ are possible by using micro-meteorological measurement methods such as lysimeters, Bowen ratio energy balance system, eddy correlation system, and flux profile techniques (Hatfield, 1990). However, these methods are expensive and difficult to deploy and maintain in both time and space. Hence, mathematical models are commonly used for estimating $E T_{c}$ over the entire range of crop development stages. Many studies show that the Penman-Monteith equation is able to estimate $E T_{0}$ from weather data under diverse climatic conditions with a reasonable accuracy (Amatya et al., 1995; Ventura et al., 1999; Irmak et al., 2008; Temesgen et al., 2005; Yoder et al., 2005; Lopez-Urrea et al., 2006). Several Penman-Monteith (Monteith, 1965)-type combination-based energy balance modeling approaches have been employed to estimate $E T_{c}$ by separately taking into account soil surface and plant canopy conditions. These approaches include multilayer Penman-Monteith-type methods (Shuttleworth and Wallace, 1985; Shuttleworth and Gurney, 1990; Choudhury and Monteith, 1988; Norman et al., 1995; Kustas and Norman, 1999; Gardiol et al., 2003; Lagos et al., 2009; Guan and Wilson, 2009) and the dual crop coefficient (dual-K) method (Jensen et al., 1971; Wright and Jensen, 1978; Wright, 1981, 1982).

The $K_{c}$ method was originally developed and proposed by van Wijk and de Vries (1954). Jensen et al. (1971), Wright and Jensen $(1978)$, and Wright $(1981,1982)$ have improved the $K_{c}$ concept. These procedures, including dual- $K_{c^{\prime}}$ were also adopted by the Food and Agriculture Organization of the United Nations Irrigation and Drainage Paper No. 56 (FAO-56, 1998). The dual- $K_{c}$ method is simpler compared to the heavily-parameterized multi-layer models and may therefore be more suitable for operational applications where daily estimates of $E T_{c}$ are needed. The dual- $K_{c}$ method separately estimates daily crop transpiration $(T)$ and soil evaporation $\left(E_{s}\right)$ from reference grass evapotranspiration $\left(E T_{o}\right)$ by applying two coefficients, namely, the basal crop coefficient $K_{c b}$ and a soil water evaporation coefficient $K_{e}$ (dual- $K_{c}=K_{c b}+K_{e}$ ). The basal crop coefficient $\left(K_{c b}\right)$ is crop-specific and represents the ratio of $E T_{c}$ to $E T_{0}$ under conditions when the soil surface layer is dry, so that $E_{s}$ is minimal, but the average soil water content in the root zone is adequate to sustain crop transpiration at a potential rate. The soil water evaporation coefficient $\left(K_{e}\right)$ is the ratio of $E_{s}$ to $E T_{o}$ and represents the evaporation from wet soil, which occurs in addition to soil water evaporation included in $K_{c b}$. When using the dual- $K_{c}$ method, $K_{c b}$ values are adjusted for local climate and plant water stress conditions, and the $K_{e}$ values are adjusted for surface soil wetness.

Although the dual- $K_{c}$ method may provide a more precise approach of determining $E T_{c}$ in a soil-residue-crop system, the single- $K_{c}$ method is still widely used to estimate $E T_{c}$ for irrigation scheduling on an operational basis. In the single crop coefficient (single- $K_{c}$ ) method (Jensen et al., 1970; Doorenbos and Pruitt, 1977), the effect of both $T$ and $E_{s}$ are integrated into a single crop-specific coefficient with no direct adjustment made for the effects of residue cover and surface soil wetness on $E_{s}$. However, adjustments can be made for the effects of limiting soil moisture on $T$ using a plant water stress coefficient. The performance of both single- $K_{c}$ and dual- $K_{c}$ methods depends on accurate selection of representative coefficient values for each of the four crop growth stages (initial, crop development, mid-season, and late-season), identification of the locally ad- justed lengths of the growth stages, and accurate estimation of $E T_{o}$ from climatic parameters. While the FAO-56 (FAO-56, 1998) presents tables of crop coefficients and lengths of crop growth stages for various crops, these values are only "average" values and may not be valid for various conditions. Use of average FAO table values of crop coefficients and lengths of growth stages without local adjustment could introduce inaccuracies in the estimated $E T$. Because crop coefficients and lengths of growth stages are influenced by many factors including plant species (including hybrids/cultivars), soils, management practices (i.e., population density, row spacing, disease and weed control, irrigation, etc.), and climatic conditions, they should ideally be derived experimentally for each crop and region under various management practices for more accurate and representative estimation of $E T$. However, this is rarely done due to the complexity and costs involved.

Given the tremendous amount of variability in soil and crop management practices and climatic conditions that can influence the performance of the single- $K_{c}$ and dual $-K_{c}$ methods to estimate $E T_{c}$, very few studies have been conducted to quantify, evaluate, and compare the accuracy of the single- $K_{c}$ and dual- $K_{c}$ methods for estimation of $E T_{c}$ in crop systems. Lui and Pereira (2000) evaluated the single- $K_{c}$ and dual- $K_{c}$ methods with measured crop evapotranspiration $\left(E T_{m}\right)$ data and found the dual- $K$ method to perform better than the single- $K$ method. Tolk and Howell (2001) compared daily ET $m$ of limited and fully-irrigated grain sorghum to $E T_{c}$ calculated using single- $K_{c}$ and dual- $K_{c}$ with $E T_{o}$. With the dual- $K_{c}$ procedure, they found that the difference between cumulative $E T_{c}$ and $E T_{m}$ during the season varied substantially from $2 \mathrm{~mm}$ to around $70 \mathrm{~mm}$, and by the end of the season the maximum difference between $E T_{c}$ and $E T_{m}$ was about $60 \mathrm{~mm}$ or $10 \%$. The single- $K_{c}$ procedure significantly underestimated final $\mathrm{cu}-$ mulative $E T_{m}$ in the fully irrigated treatments by as much as $120 \mathrm{~mm}$. ShiZhang et al. (2007) compared $E T_{m}$ with $E T_{c}$ estimated using single- $K_{c}$ and dual- $K_{c}$ for late rice crop. They found that the relative error between $E T_{m}$ and $E T_{c}$ estimated by the single- $K_{c}$ and dual- $K_{c}$ varied within $12.4-16.2 \%$, and that the dual- $K_{c}^{c}$ gave better estimates than the single- $K_{c}$. Majnooni-Heris et al. (2007) evaluated daily $E T_{c}$ of maize crop for two crop seasons using single- $K_{c}$ and dual- $K_{c}$ methods. They found the seasonal total $E T_{c}$ estimated by the dual- $K_{c}$ method to be greater than those estimated by the single- $K_{c}$ method by 78 and $68 \mathrm{~mm}$ during the two crop seasons.

The accuracy of $E T_{c}$ estimated using the single- $K_{c}$ and dual$K_{c}$ methods as impacted by crop residue left on the soil surface is unknown. The overall objective of this study is to determine whether the more computationally-involved dual- $K_{c}$ method improves prediction of $E T_{c}$ in conservation tillage cropping systems, which leaves substantial crop residue on the soil surface, as compared with the single- $K_{c}$ method. The specific objectives were: (1) to evaluate and compare the accuracy and robustness of the single- $K_{c}$ and dual- $K_{c}$ methods for estimation of daily $E T$ of soybean in a subsurface drip-irrigated field with partial surface residue cover, and (2) to determine the magnitude by which $E T_{c}$ is reduced for each $10 \%$ of soil surface covered with crop residue.

\section{Materials and methods}

\subsection{Description of study site and measurements}

The datasets for this study were obtained from field research (Irmak and Mutiibwa, 2009a, 2009b) conducted in a 13.5 ha subsurface drip-irrigated soybean field during the 2007 and 2008 growing seasons (May-October). The experimental field is located at the University of Nebraska-Lincoln, South Central Agricultural Laboratory (SCAL) near Clay Center, Nebraska (latitude $40^{\circ} 34^{\prime} \mathrm{N}$ and longitude $98^{\circ} 8^{\prime} \mathrm{W}$ at an elevation 
of $552 \mathrm{~m}$ above mean sea level). The climate at Clay Center is described as sub-humid with warm and dry summers and very cold and extremely windy winters with average temperatures below $0{ }^{\circ} \mathrm{C}$. The warmest month of the year is usually July with an average maximum temperature of $30.9^{\circ} \mathrm{C}$, while the coldest month of the year is January with an average minimum temperature of $-11.1^{\circ} \mathrm{C}$. The long-term (1982-2008) annual average precipitation at Clay Center is about $700 \mathrm{~mm}$. Rainfall is not evenly distributed throughout the year. The wettest month of the year is May with an average rainfall of $120 \mathrm{~mm}$. The soil in the field is classified as Hastings silt loam which is well drained soil with a $0.5 \%$ slope. The particle size distribution is $15 \%$ sand, $62.5 \%$ silt, $20 \%$ clay, and $2.5 \%$ organic matter content. The soil field capacity $\left(\theta_{f c}\right)$ is $0.34 \mathrm{~m}^{3} \mathrm{~m}^{-3}$, permanent wilting point $\left(\theta_{w w p}\right)$ is $0.14 \mathrm{~m}^{3} \mathrm{~m}^{-3}$, and the saturation point $\left(\theta_{\text {sat }}\right)$ is $0.51 \mathrm{~m}^{3} \mathrm{~m}^{-3}$ (Irmak et al., 2008; Irmak and Mutiibwa, 2009a, 2009b; Irmak, 2010).

In 2007, the field was planted with soybean (variety Pioneer 93M11) seeds on May 21 at a rate of 156,000 plants per hectare with a planting depth of $0.025 \mathrm{~m}$ and row spacing of $0.76 \mathrm{~m}$ with an east-west planting direction. Plants emerged on May 26 and were harvested on October 24, 2007. In 2008, the field was again planted with the same soybean variety on May 19, at the same planting density, planting depth, and row spacing as in 2007. Plants emerged on May 24 and were harvested on October 1, 2008. The subsurface drip irrigation (SDI) laterals were placed in the middle of every other row $(1.52 \mathrm{~m})$ and at a depth of approximately $0.40 \mathrm{~m}$. Irrigation was applied seven times during the 2007 crop season and four times during the 2008 growing seasons. The available soil water in the effective root zone was maintained at maximum allowable depletion of approximately $45 \%$ of plant-available soil water during the mid-season growth stage to avoid crop water stress. Leaf area index ( $L A I)$ was measured using a model LAI-2000 plant canopy analyzer (LI-COR Biosciences, Lincoln, Nebraska, USA). On average, a total of 60 LAI measurements were taken on each measurement day and averaged for the day with measurements starting when $L A I$ was approximately 1.10 (32 DAP). On each LAI measurement day, plant height $(h)$ measurements were taken by measuring from the soil surface to the tip of the tallest leaf from approximately 15 randomlyselected plants and the values were averaged for that day (Mutiibwa and Irmak, 2011).

The evaporative flux $\left(E T_{m}\right)$ above the crop canopy was measured by the Bowen ratio energy balance system (BREBS). The Bowen ratio formula (Bowen, 1926) for evaporative flux measurement is derived from the energy balance of the canopy surface and expressed as:

$$
R_{n}-G=H+\lambda E T_{c}
$$

where $R_{n}=$ net radiation above crop canopy, $G=$ soil heat flux, $H=$ sensible heat flux, and $\lambda E T_{c}=$ latent heat flux (all units in $\mathrm{W} \mathrm{m} \mathrm{m}^{-2}$ ). Equation (1) can be rewritten in the following form:

$$
E T_{c}=\frac{\left(R_{n}-G\right)}{\lambda(1+\beta)}
$$

where $\beta=$ Bowen ratio $H / \lambda E T_{c}$ (dimensionless) and is calculated from measurements of air temperature and vapor pressure gradients taken at two heights above the crop canopy and within the boundary layer of the surface. Assuming that the transfer coefficients of heat and water vapor are equal, it can be shown that (Bowen, 1926; Tanner, 1960):

$$
\beta=\frac{H}{\lambda E T_{c}}=\frac{\gamma \partial T_{a}}{\partial e}
$$

where $r=$ psychometric constant $\left(\mathrm{kPa}{ }^{\circ} \mathrm{C}\right)$, and $\partial \mathrm{T}_{a} / \partial e$ is the gradient of the air temperature $\left(T_{\mathrm{a}}\right)$ and vapor pressures $(e)$ for heights of 0.3-3.0 m. Measurements of $H, G, R_{n^{\prime}} T_{a}$ and $e$ were made using a deluxe version of a BREBS (Radiation and En- ergy Balance Systems, REBS, Inc., Bellevue, WA, USA) that was installed in the middle of the experimental field. The fetch distances were $520 \mathrm{~m}$ in the north-south direction and $280 \mathrm{~m}$ in the east-west direction. $T_{a}$ and relative humidity $(R H)$ were measured using two platinum resistance thermometers and monolithic capacitive humidity sensors (REBS Models THP04015 and THP04016, respectively). The BREBS used an automatic exchange mechanism that physically exchanged the $T_{a}$ and $R H$ sensors between two heights above the canopy. The lower exchanger sensors level was maintained at an average height of $1 \mathrm{~m}$ above the canopy as the crop grew, and the distance between the upper and lower exchanger sensors was kept at a constant distance of $1 \mathrm{~m}$. Incoming and outgoing shortwave radiation were measured simultaneously using REBS model THRDS7.1 double sided total hemispherical radiometer. $R_{n}$ was measured using a REBS Q*7.1 net radiometer. Both radiometers were installed at $4.5 \mathrm{~m}$ above the ground surface. $G$ was measured using three REBS HFT-3.1 heat flux plates and three REBS STP-1 soil thermocouple probes. Each pair of soil heat flux plate and soil thermocouple was placed at a depth of $0.08 \mathrm{~m}$ below the soil surface in close proximity to each other. Measured $G$ was adjusted for soil temperature and soil moisture content (Irmak, 2010). The BREBS and other datasets used in this study are part of the Nebraska Water and Energy Flux Measurement, Modeling, and Research Network (NEBFLUX) (Irmak, 2010) that operates ten deluxe versions of BREBS and one eddy covariance system over various vegetation surfaces. Detailed description of the microclimate measurements, including $\lambda E T_{c^{\prime}} H, G, R_{n^{\prime}}$ and other microclimatic variables (actual vapor pressure, $T_{a^{\prime}}^{n^{\prime}} R H$, wind speed and direction, incoming and outgoing shortwave radiation, albedo, and soil temperature) are presented in Irmak (2010).

The daily weather data (incoming shortwave radiation, air temperature, relative humidity, wind speed, and precipitation) used for the calculation of $E T_{\text {o }}$ was obtained from an automated weather station (AWS) located approximately $1 \mathrm{~km}$ from the experimental field and operated by the High Plains Regional Climate Center (HPRCC): http://hprcc1.unl.edu/ cgi-hpcc/home.cgi. The HPRCC-AWS consisted of standard instruments used for measuring climatic variables and was maintained on a natural grass. The fetch condition was adequate in all directions of the weather station. No corrections or adjustments were applied to the weather data as the HPRCC applies vigorous quality and integrity of the collected microclimatic data on a real-time basis.

\subsection{Calculation of grass-reference evapotranspiration (ET $)$}

Grass-reference evapotranspiration $\left(E T_{0}\right)$ was calculated using the ASCE form of the Penman-Monteith (ASCE-EWRI PM) equation (ASCE-EWRI, 2005), which is essentially the original Penman-Monteith equation with an assumed fixed canopy resistance for a hypothetical grass-reference surface. The Penman-Monteith grass-reference equation for a daily time step is expressed as:

$$
E T_{o}=\frac{0.408 \Delta\left(R_{n}-G\right)+\gamma\left(C_{n} /(T+273)\right) u_{2}\left(e_{s}-e_{a}\right)}{\left[\Delta+\gamma\left(1+C_{d} u_{2}\right)\right]}
$$

where $E T_{0}=$ grass-reference evapotranspiration $\left(\mathrm{mm} \mathrm{d}^{-1}\right)$, $\Delta=$ slope of saturation vapor pressure versus air temperature curve $\left(\mathrm{kPa}^{\circ} \mathrm{C}^{-1}\right), R_{n}=$ net radiation $\left(\mathrm{MJ} \mathrm{m} \mathrm{m}^{-2} \mathrm{~d}^{-1}\right), G=$ soil heat flux $\left(\mathrm{MJ} \mathrm{m}^{-2} \mathrm{~d}^{-1}\right), T=$ mean daily air temperature $\left({ }^{\circ} \mathrm{C}\right)$, $u_{2}=$ mean daily wind speed at $2-\mathrm{m}$ height $\left(\mathrm{m} \mathrm{s}^{-1}\right), e_{s}=$ saturation vapor pressure $(\mathrm{kPa}), e_{a}=$ actual vapor pressure $(\mathrm{kPa})$, $\left(e_{s}-e_{a}=\right.$ vapor pressure deficit, $\left.V P D\right), r=$ psychometric constant $\left(\mathrm{kPa}{ }^{\circ} \mathrm{C}\right), C_{\eta}=$ numerator constant that changes with reference surface $\left(900^{\circ} \mathrm{C} \mathrm{mm} \mathrm{s}^{3} \mathrm{Mg}^{-1} \mathrm{~d}^{-1}\right.$ for grass), $\mathrm{C}_{d}=$ denominator constant that changes with reference surface $\left(0.34 \mathrm{~s} \mathrm{~m}^{-1}\right.$ for grass). Procedures for calculating the various parameters 
of Equation (4) from measured weather data [solar radiation $\left(R_{s}\right), R H$, wind speed measured at $2 \mathrm{~m}\left(u_{2}\right)$, and air temperature $\left(T_{a}\right)$ ] are outlined in ASCE-EWRI (2005).

\subsection{Calculation of $E T_{c}$ using single- $K_{c}$ and dual-K $K_{c}$ methods}

Detailed description of procedures for applying the single$K_{c}$ and dual- $K_{c}$ methods to estimate $E T_{c}$ is given in FAO-56. Single- $K_{c}$ method estimates $E T_{c}$ using the equation:

$$
E T_{c}=K_{s} K_{c} E T_{o}
$$

and the dual- $K_{c}$ method estimates $E T_{c}$ using:

$$
E T_{c}=\left(K_{s} K_{c b}+K_{e}\right) E T_{o}
$$

where $E T_{0}=$ grass reference evapotranspiration, $K_{c}=$ single crop coefficient, $K_{c b}=$ basal crop coefficient, $K_{s}=$ soil water stress coefficient, and $K_{e}=$ soil water evaporation coefficient. Appropriate $K_{c}$ and $K_{c b}$ values for soybean were taken from FAO-56, which are derivatives of the values which were originally introduced and published by Doorenbos and Pruitt (1977) in FAO-24. The $K_{c}$ table in FAO-24 had multiple entries for four wind and $\mathrm{RH}$ classes. These FAO-24 $K_{c}$-values have been condensed into one column of values in FAO-56 representing $K_{c}$-values for standard climatic conditions defined as a sub-humid climate having average daytime minimum relative humidity $\left(R H_{\text {min }}\right)=45 \%$ and having calm to moderate wind speeds $\left(u_{2}\right)$ averaging $2 \mathrm{~m} \mathrm{~s}^{-1}$. For climate with $R H_{\text {min }} \neq 45 \%$ or $u_{2}$ at $2 \mathrm{~m} \neq 2 \mathrm{~m} \mathrm{~s}^{-1}$, the coefficients are adjusted according to the following equation (Pereira et al., 1996):

$$
K_{\text {adj }}=K_{\text {table }}+\left[0.04\left(u_{2}-2\right)-0.004\left(R H_{\min }-45\right)\right](\mathrm{h} / 3)^{0.3}
$$

where $K_{\text {table }}=K_{c}$ or $K_{c b}$ values taken from the FAO-56 tables, and $K_{a d j}=K_{c}$ or $K_{c b}$ adjusted for the local climatic conditions. The $K_{s}$ concept was first introduced by Jensen et al. (1971) to account for increased evaporation occurring when the soil surface is partially or completely wetted by irrigation or precipitation. The $K_{S}$ was estimated as:

and

$$
K_{s}=\frac{\left(T A W-D_{r}\right)}{(1-p) T A W} \text { for } D_{r}>R A W
$$

$$
\begin{aligned}
& T A W=1000\left(\theta_{F c}-\theta_{W P}\right) Z_{r} \\
& R A W=p T A W
\end{aligned}
$$

where $D_{\mathrm{r}}=$ root zone depletion, defined as water shortage relative to field capacity (mm), RAW = readily available soil water in the root zone $(\mathrm{mm}), T A W=$ total available soil water in the root zone (mm), $p=$ fraction of TAW that a crop can extract from the root zone without suffering water stress, $\theta_{F c}=$ soil water content at field capacity $\left(\theta_{F c}=0.34 \mathrm{~m}^{3} \mathrm{~m}^{3}\right), \theta_{W P}=$ soil water content at permanent wilting point $\left(\theta_{W P}=0.14 \mathrm{~m}^{3} \mathrm{~m}^{3}\right)$, and $Z_{r}=$ the effective rooting depth $(\mathrm{m})$. The initial effective depth at planting $\left(Z_{r \text { min }}=0.1 \mathrm{~m}\right)$ and the maximum effective depth occurring at mid-season $\left(Z_{r \max }=1.2 \mathrm{~m}\right)$ of soybean were used. The development of the root zone was assumed to increase in proportion to the increase in $K_{c b}$. The value of $p$ varies with atmospheric evaporative demand, crop characteristics and soil type. Doorenbos et al. (1986) suggest $p$ values for different crops ranging between 0.125 and 0.7 for an atmospheric evaporative demand varying from $2 \mathrm{~mm}$ to $10 \mathrm{~mm} \mathrm{~d}^{-1}$. Several authors show that the $p$ value for soybean is between 0.4 and 0.6 (Doorenbos et al., 1986; Rosadi et al., 2007; Raes et al., 2009). An average of $p=0.5$ as suggested for the FAO AquaCrop model (Raes et al., 2009) was used in the study.

The calculation of root zone depletion $\left(D_{r}\right)$ employs a daily water balance computation for the root zone expressed as:

$$
D_{r, i}=D_{r, i-1}-\left(P_{i}-R O_{i}\right)-I_{i}-q_{i}+E T_{c, i}+D P_{i}
$$

where $D_{r, i}=$ root zone depletion at the end of day $i(\mathrm{~mm})$, $D_{r, i-1}=$ depletion in the root zone at the end of the previous day, $i-1(\mathrm{~mm}), P_{i}=$ precipitation on day $i(\mathrm{~mm}), R O_{j}=$ runoff from the soil surface on day $i(\mathrm{~mm}), I_{i}=$ net irrigation depth on day $i$ that adds to root zone water content (mm), $q_{i}=$ capillary rise from groundwater table on day $i(\mathrm{~mm}), E T_{c, i}=\mathrm{ac}-$ tual crop evapotranspiration on day $i(\mathrm{~mm})$, and $D P_{i} \stackrel{c, i}{=}$ deep percolation from the root zone on day $i(\mathrm{~mm})$. The study field was flat and groundwater table low, hence $R O_{i}$ and $q_{i}$ were assumed to be zero.

The sum of $K_{c b}$ and $K_{e}$ in Equation (6) cannot exceed some maximum value $\left(K_{c \max }\right)$ which defines an upper limit on the evaporation and transpiration from any cropped surface based on the available latent energy. $K_{c \max }$ was calculated for grass reference $E T_{o}$ as:

$$
\begin{aligned}
K_{c \max }= & \left\langle\operatorname { m a x } \left\{ 1.2+\left(\frac{h}{3}\right)^{0.3}\left[0.04\left(u_{2}-2\right)\right.\right.\right. \\
& \left.\left.\left.-0.004\left(R H_{\min }-45\right)\right]\right\}\left(K_{c b}+0.05\right)\right\rangle
\end{aligned}
$$

where $h=$ mean maximum plant height $(\mathrm{m})$ and max indicates the selection of the maximum value within the brackets \{\} . The $K_{e}$ was adjusted for the soil surface wetness using the following equation:

$$
K_{e}=K_{r}\left(K_{c \max }-K_{c b}\right) \leq f_{e w} K_{c \max }
$$

where $K_{r}=$ a dimensionless evaporation reduction coefficient and $f_{e w}=$ the fraction of the soil that is both exposed to solar radiation and that is wetted. $K_{r}$ was calculated as:

$$
K_{r}=\frac{\left(T E W-D_{e, i-1}\right)}{(T E W-R E W)}
$$

and

$$
T E W=1000\left(\theta_{F c}-0.5 \theta_{W P}\right) Z_{e}
$$

where $T E W=$ total evaporable water defined as the maximum depth of water that can be evaporated from the soil when the top soil has been initially completely wetted $(\mathrm{mm}), D_{e, i-1}=\mathrm{cu}-$ mulative depth of evaporation from the soil surface layer at the end of day $i-1(\mathrm{~mm}), Z_{e}=$ depth of the surface soil layer that is drying by evaporation $(\mathrm{m})$, and $R E W=$ readily evaporable water $(\mathrm{mm})$. Average typical values of $Z_{e}$ and $R E W$ for silt loam soil $\left(Z_{e}=0.1 \mathrm{~m}\right.$ and $\left.R E W=9.5 \mathrm{~mm}\right)$ were used.

Because the study field was irrigated by a subsurface drip irrigation system with drip laterals buried at $0.4 \mathrm{~m}$ below the soil surface, soil surface wetting was only by precipitation which was assumed to be evenly distributed over the soil surface (crop canopy sometimes redistributes rainfall over the soil surface). The effective fraction of the soil surface covered by crop canopy was estimated as:

$$
f_{c}=\left[\frac{\left(K_{c b}-K_{c \min }\right)}{\left(K_{c \max }-K_{c \min }\right)}\right]^{(1+0.5 h)}
$$

where $f_{c}=$ effective fraction of the soil surface covered by crop canopy, $K_{c \text { min }}=$ minimum $K_{c}$ for bare soil with no ground cover $(\approx 0.15)$, and $h=$ mean plant height. Therefore, the fraction of the soil that is exposed to solar radiation and air ventilation and from which the majority of $E_{S}$ takes place is expressed as $\left(1-f_{c}\right)$.

Lastly, adjustments were made on the estimated $E T_{c}$ to account for the effects of residue cover on $E_{s}$. A general rule of thumb is to reduce $E_{s}$ by about $5 \%$ for each $10 \%$ of the soil surface that is covered by crop residue. For example, when $60 \%$ of the soil surface is covered by crop residue, then soil evaporation is reduced by $30 \%$. To apply this to the single- $K_{c}$ method, single$K_{c}$ values during the initial crop growth stage $\left(K_{c i n i}\right)$ are reduced by about $30 \%$, and single- $K_{c}$ values during the mid-season crop growth stage $\left(K_{c \text { mid }}\right)$ are reduced by $30 \%$ of the difference be- 
tween $K_{c \text { mid }}$ and $K_{c \text { ini }}$. If the same adjustment is applied to the dual $-K_{c}$ method, the magnitude of $E_{s}$ is reduced by $30 \%$.

\subsection{Estimation of surface residue cover}

The study used the relationship between measured crop yield and crop residues produced (Wortmann et al., 2008) and tables of typical percent residue remaining after winter-weathering and various field operations (Shelton et al., 2000) to estimate the percent of residue from the previous crop season remaining on the field surface after planting. Wortmann et al. (2008) estimate that approximately 1 ton of residue (at $10 \%$ moisture) is produced with 1.02 ton of maize grain yield and 0.82 ton of soybean. In 2007, the residue remaining on the field was from a previous maize crop harvested on October 5-6, 2006. The yield of 2006 maize crop was 11.6 ton ha ${ }^{-1}$ and the amount of residue produced at harvest was estimated at 11.4 ton ha ${ }^{-1}$. Maize residues are less fragile and are little affected by over winter-weathering. About $90 \%$ of maize residue remains after winter weathering (Shelton et al., 2000). The maize residue stalks were shredded by a stalk chopper before planting soybean crop in 2007 . The field was ridge-tilled and planted which left about $60 \%$ of residue remaining on the soil surface (Shelton et al., 2000). The final amount of surface residue remaining on the field surface at the beginning of the 2007 crop season was 6.2 ton $\mathrm{ha}^{-1}$ estimated by multiplying the amount of residue after harvest by the percent residue remaining after winter-weathering and the percent residue remaining after planting operations. The 2007 soybean crop was harvested in October 2007, and the combine-measured yield and estimated amount of residue produced were 4.7 ton ha-1 and 5.7 ton ha ${ }^{-1}$, respectively. Soybean residues are fragile and are reduced by over winter-weathering to about 75\% (Shelton et al., 2000). In 2008 the field was not tilled but ridge-planted with soybean in May 2008 which resulted in little or no change of surface residue remaining on the soil surface. The final amount of residue remaining at the beginning of the 2008 crop season was 4.3 ton ha ${ }^{-1}$ estimated by multiplying the amount of residue after harvest by the percent residue remaining after winter weathering.

The amounts of residue remaining at the field surface was evenly distributed and continued to decrease during the growing season due to residue decomposition. Residue decomposition is controlled mainly by environmental factors, primarily temperature and moisture content of residue layer (Gregory et al., 1985; Roper, 1985), carbon/nitrogen (C/N) ratio of the residue (Meentemeyer, 1978; Parr and Papendick, 1978; Aber and Melillo, 1982; Reinertsen et al., 1984), solar radiation and humidity. The daily amount of residue remaining on the soil surface was estimated using a first order exponential decomposition function (Steiner et al., 1999):

$$
M_{t}=M_{o} \exp ^{-k_{d}(D C D)}
$$

where $M_{t}$ is total residue mass at time $t$ (ton ha ${ }^{-1}$ ), $M_{o}$ is the initial mass at the beginning of the crop season (ton ha ${ }^{-1}$ ), $k_{d}$ is a crop-specific decomposition coefficient (ton ton ${ }^{-1} \mathrm{~d}^{-1}$ ), and $D C D$ is decomposition days. The coefficient $k_{d}$ accounts for the differences in $\mathrm{C} / \mathrm{N}$ ratio and physical properties of the residues and reported values for legume residues are significantly higher than those of cereal residues. Steiner et al. (1999) and Quemada (2004) reported $k_{d}$ values ranging from 0.015 to 0.042 for cereal residues while van Donk et al. (2008) reported $k_{d}$ values ranging from 0.02 to 0.03 for legume residues and 0.013 to 0.015 for cereal residues. The values $k_{d}=0.030$ for soybean residue and $k_{d}=0.015$ for maize residue were used in this study. DCD is calculated as a function of daily air temperature and residue moisture coefficients. Daily temperature and moisture coefficients (TC and $M C$, respectively) are calculated and constrained from 0 to 1 , with 1 indicating conditions for maximum decomposition and 0 indicating no decomposi- tion. Based on the principle of most limiting factor, the $D C D$ for a given day is equal to the minimum of TC or MC and expressed as:

$$
D C D=\min (T C, M C)
$$

The coefficient TC is calculated using the procedures proposed by Steiner et al. (1994):

$$
T C=\frac{2 T_{a}^{2}\left(T_{o p t}\right)^{2}-T_{a}^{4}}{\left(T_{o p t}\right)^{4}}
$$

where $T_{a}$ is daily average air temperature $\left({ }^{\circ} \mathrm{C}\right)$, and $T_{\text {opt }}$ is the optimum air temperature for residue decomposition $\left(T_{\text {opt }}=32{ }^{\circ} \mathrm{C}\right)$. In calculating $M C$, it is assumed that $4 \mathrm{~mm}$ of precipitation is enough to fully wet a layer of residues (Steiner et al., 1994). If precipitation for a given day is more than $4 \mathrm{~mm}$, the precipitation coefficient $(P C)$ is set to 1 , and for precipitation below $4 \mathrm{~mm}, P C$ is equal to precipitation divided by 4 . $M C$ was calculated (Steiner et al., 1994) as:

$$
\begin{gathered}
M C_{t}=0.5 M C_{t-1}+P C_{t} \quad\left(M C_{t}=1.0 \quad \text { when } M C_{t}>1.0\right) \\
P C_{t}=1.0 \quad \text { when } P_{t} \geq 4.0 \mathrm{~mm} \\
P C_{t}=P_{t} \div 4 \quad \text { when } P_{t}<4.0 \mathrm{~mm}
\end{gathered}
$$

where $P_{t}$ is the current day precipitation $(\mathrm{mm}), P C_{t}$ is precipitation coefficient for the current day, and $M C_{t}$ and $M C_{t-1}$ are the moisture coefficients for the current and previous day, respectively. The fraction of soil surface covered with crop residue $\left(C_{r}\right)$ was estimated as a function of the mass of residue (Gregory, 1982) which is expressed as:

$$
C_{r}=1-\exp \left(-A_{m} M_{t}\right)
$$

where $A_{m}$ is an empirical parameter that converts mass to an equivalent area and varies with residue characteristics and randomness of distribution. Reported values of $A_{m}$ for maize and soybean are 0.32 and 0.20, respectively (Gregory, 1982).

\subsection{Analyses and statistics}

The predictive qualities of the single- $K_{c}$ and dual $-K_{c}$ methods were evaluated by comparing estimated evapotranspiration $\left(E T_{c}\right)$ against BREBS-measured evapotranspiration $\left(E T_{m}\right)$ using graphical presentations and statistical parameters. The goodness-of-fit between $E T_{m}$ and $E T_{c}$ was evaluated using the coefficient of determination $\left(R^{2}\right)$, the modified coefficient of efficiency $(E)$ proposed by Legates and McCabe (1999), and cumulative $E T_{m}$ and $E T_{c}$. The $R^{2}$ describes the proportion of total variance in the measured data that is explained by the estimates. It ranges from 0.0 to 1.0 , with higher values indicated better agreement. However, $R^{2}$ is insensitive to additive and proportional differences between datasets. Because of these limitations, $E$ was used as an additional measure to verify the agreements between $E T_{m}$ and $E T_{c^{*}}$. $E$ is expressed as:

$$
E=1.0-\frac{\sum_{i=1}^{n}\left(X_{i}-Y_{i}\right)^{2}}{\sum_{i=1}^{n}\left(X_{i}-\bar{X}\right)^{2}}
$$

where $X=$ measured data, $Y=$ estimated data, $n=$ size of the sample data, $i=$ number of order of variable in the sample, and $\bar{X}=$ mean of $X$. The statistic $E$ examines whether the difference between measured and estimated data is as large as the variability in the measured data. The possible $E$ values range from $-\infty$ to 1 , with higher values indicating better agreement between the measured and estimated data. An $E$ value of 0 indicates that the estimated data is only as good as the mean of the measured data, while a negative $E$ value indicates that the mean of the measured data is better than the estimated data. $E$ represents an improvement over $R^{2}$ in that it is sensitive to differences in measured and estimated means and vari- 


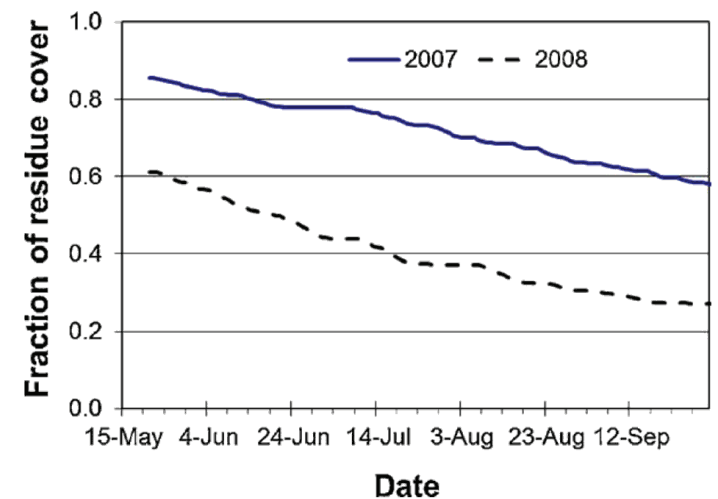

Figure 1. Estimated fraction of soil surface covered with crop residue during the crop growing seasons in 2007 and 2008.

ances, and will always be lower than that value (Legates and McCabe, 1999).

For error analysis, the root mean square difference (RMSD) and mean bias error (MBE) were used. Both RMSD and $M B E$ represent the average difference between measured and estimated datasets. The RMSD measures the non-systematic variation between datasets and the $M B E$ measures the systematic variation between datasets. The RMSD and MBE are expressed as:

$$
\begin{aligned}
& R M S D=\sqrt{\frac{1}{n} \sum_{i=1}^{n}\left(X_{i}-Y_{i}\right)^{2}} \\
& M B E=\frac{1}{n} \sum_{i=1}^{n}\left(X_{i}-Y_{i}\right)
\end{aligned}
$$

To ascertain statistical significant differences between the measured and estimated evapotranspiration and between single- $K_{c}$ and dual $-K_{c}$ estimated evapotranspiration, a two-sample $t$-test of significance for analyzing the difference between the means of two datasets was added in our analysis. A $t$ test was calculated at $5 \%$ critical value for rejection $(\alpha=0.05)$. Analysis of variance (ANOVA) at 5\% critical value for rejection $(\alpha=0.05)$ was calculated to test the null hypothesis of equality in the means of estimated $E T_{c}$ values obtained by different levels of $E_{s}$ reduction in the dual- $K_{c}$ method. Both $t$-test and ANOVA were performed by statistical functions in Excel 2010 (Microsoft 2010).

\section{Results and discussions}

\subsection{Crop residue cover and canopy shading}

Data are presented showing the fraction of soil surface covered by crop residue and shaded by the canopy in 2007 and 2008 growing seasons, which may have contributed to the differences observed in estimated $E T_{c}$. The experimental field was under reduced tillage with crop residue evenly spread on the soil surface. The estimated fraction of soil surface covered with crop residue during the growing season in 2007 and 2008 are presented in Figure 1. In 2007, the fraction of residue cover decreased from about $86 \%$ in early season to about $58 \%$ at the end of the season, whereas it was about $60 \%$ in early season and $27 \%$ in late season in 2008. The year 2007 had more residue cover on the soil surface and a slower residue decomposition rate than 2008, since residue cover in 2007 was predominantly from a previous year maize crop, and residue cover in 2008 was predominantly from the soybean harvested at the end of the 2007 crop season. Maize produces more mass of less fragile residue than soybean. After mid-season growth stage, soybean leaves gradually senesce and fall onto the ground increasing the amount of surface residue cover on the soil sur-

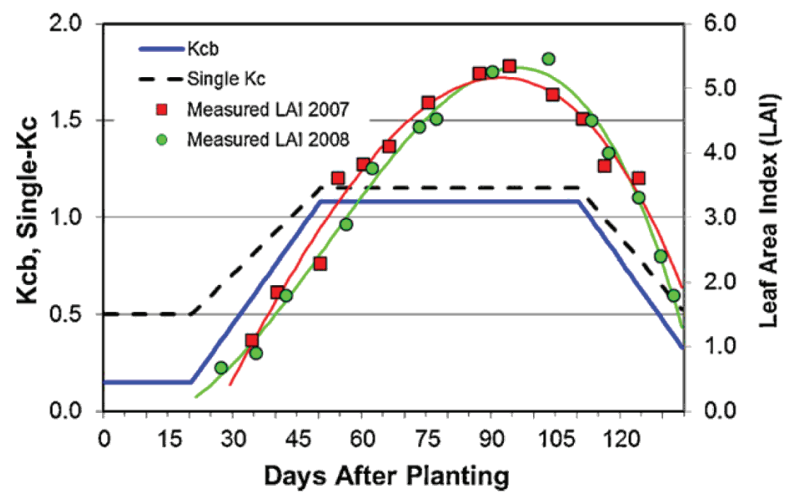

Figure 2. Crop coefficient curves and measured LAI in 2007 and 2008.

face. Crop residues on the soil surface reduce the amount of solar radiation reaching the soil surface resulting in decreased energy available for $E_{s}$. Surface residue further decreases $E_{s}$ by increasing the diffusive resistance of water vapor transport from the soil to the atmosphere (Hammel, 1996; Flury et al., 2009). Todd et al. (1991) showed that the presence of a straw mulch in a maize field significantly reduced $E_{s}$ to between 0 and $0.10 \mathrm{~mm} \mathrm{~d}^{-1}$ under dryland conditions, $0.5 \mathrm{~mm} \mathrm{~d}^{-1}$ under limited irrigation, and 0 to $1.1 \mathrm{~mm} \mathrm{~d}^{-1}$ under full irrigation. Because of the differences in percent soil surface covered with crop residue in this study, the impact of residue on $E_{s}$ between the two years (2007 and 2008) were different.

The fraction of soil surface shaded by soybean canopy is influenced by crop row spacing and seeding rates (Renner and Mickelson, 1997; Nice et al., 2001), the angle of solar radiation inclination, crop variety, and environmental factors that affect plant growth. Todd et al. (1991) showed that canopy shading
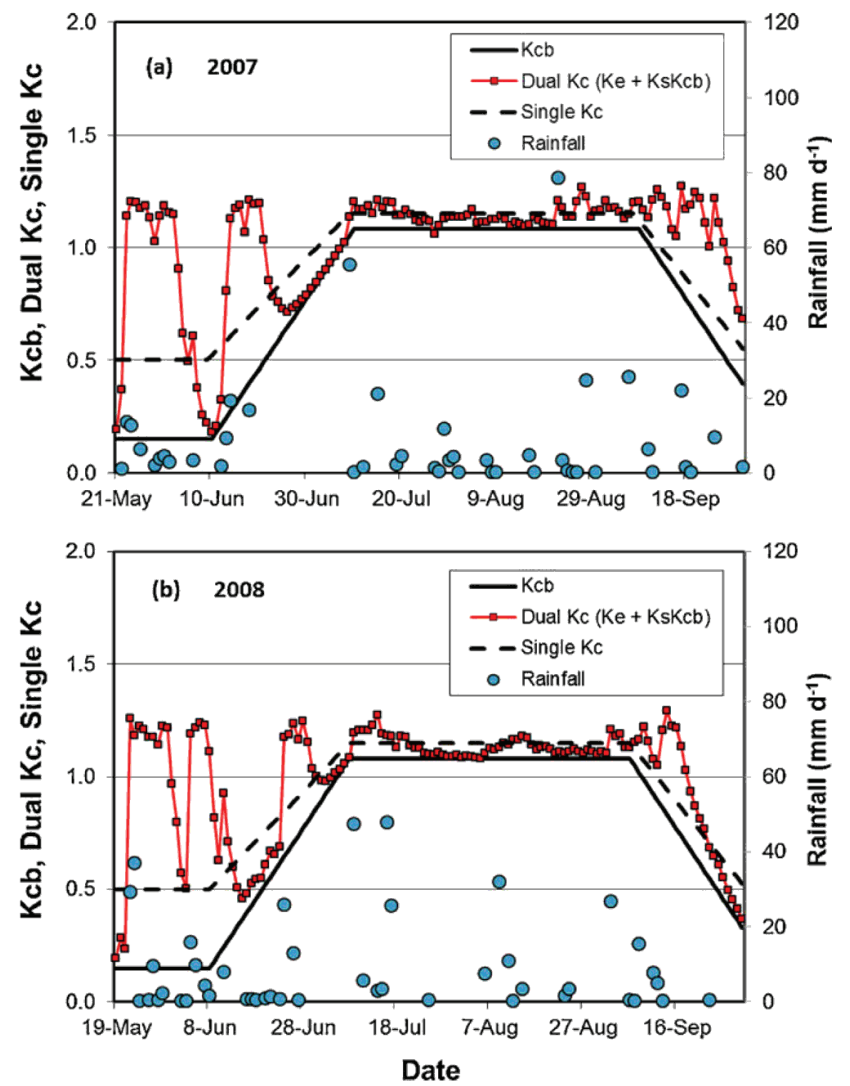

Figure 3. $K_{c b}$ single- $K_{c}$ and dual- $K_{c}$ crop curves showing the peaking of dual $-K_{c}$ following rainfall events in (a) 2007 and (b) 2008. 

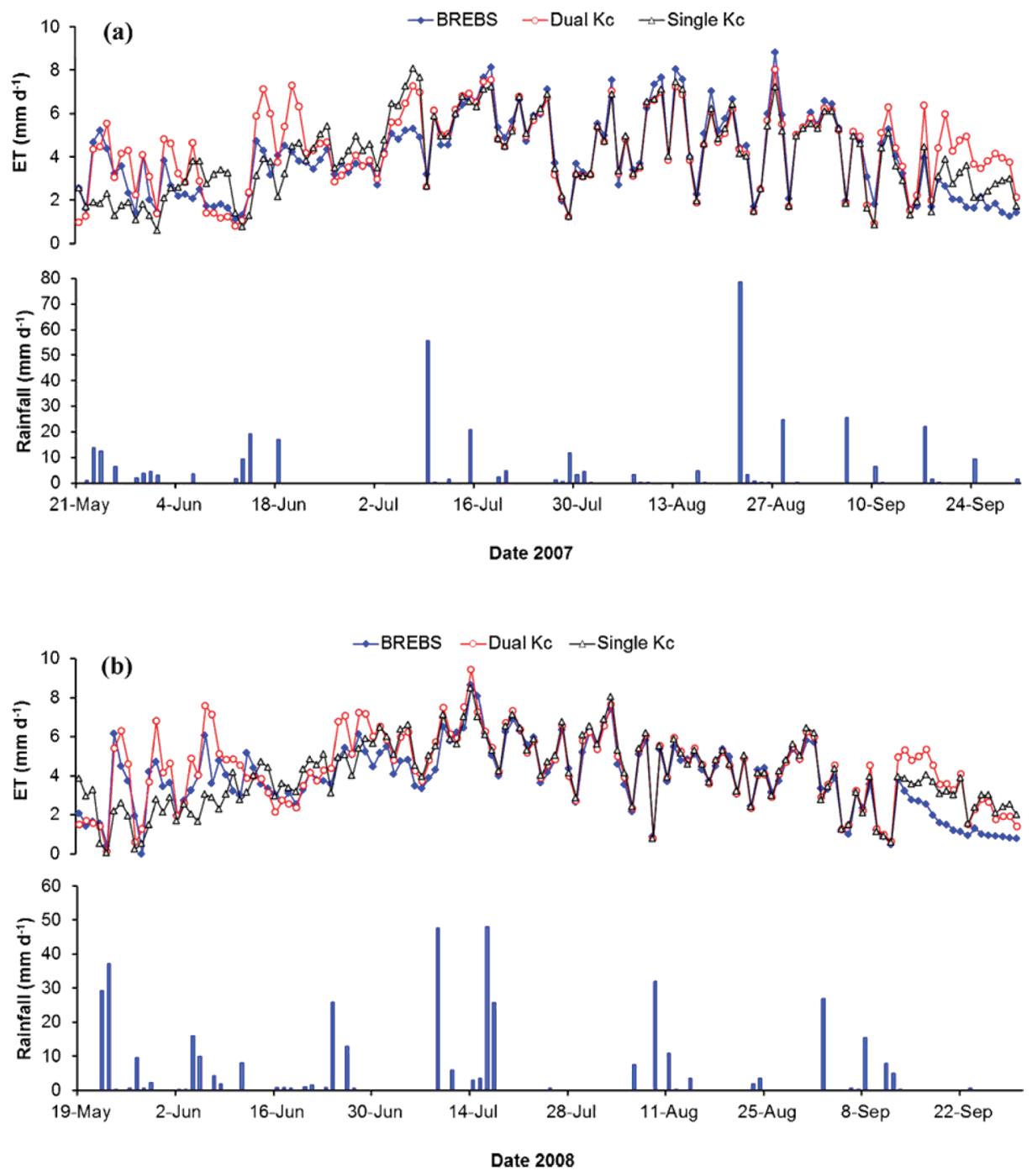

Figure 4. BREBS-measured $E T_{m}$ and $E T_{c}$ estimated using the single- $K_{c}$ and dual- $K_{c}$ methods showing similar trends and responses to changes in daily meteorological conditions throughout the growing season (a) 2007 and (b) 2008.

played a more important role in reducing $E_{s}$ than straw mulch under dryland conditions. Under limited and full irrigation, they found that crop canopy and straw mulch contributed equally to $E_{s}$ reduction. Both 2007 and 2008 crops were planted with the same soybean variety, at the same seeding rates and row spacing. Soil and plant nutrient and water management practices were also similar. Thus, the only difference between the two years was in climatic factors. The results shown in Figure 2 indicate that the difference in canopy shading between the two years was minimal.

\subsection{Basal crop coefficient, single- $K_{c^{\prime}}$ and dual-K $K_{c}$ crop curves}

The basal crop coefficient $\left(K_{c b}\right)$ and single- $K_{c}$ values for the four growth stages (initial, crop development, mid-season, and late-season) of soybean were adjusted for the local climate and soil water stress conditions. The average lengths of the growth stages of soybean for central USA were used. However, the lengths of these growth stages can be influenced by many factors, including planting date, soil temperature, soil and crop management practices, irrigation regime, and the local climatic conditions. Crop curves generated by plotting crop coefficient values versus the time of the season were graphed with measured $L A I$ in Figure 2 to show the relationship of crop coefficients to actual leaf area development. Figure 2 shows that the growth rate of LAI in both years (2007 and 2008) was slightly delayed as compared with the average growth rate for central USA. Assuming that full canopy cover for soybean is reached at $L A I=3.0$, the beginning of the mid-season growth stage appears to start later than the times suggested in the crop curve by $2 \mathrm{~d}$ in 2007 and $5 \mathrm{~d}$ in 2008 . Also assuming that the late-season stage begins with the start of decline in $L A I$, it appears that it started earlier by $12 \mathrm{~d}$ in 2007 and $8 \mathrm{~d}$ in 2008. These shifts in lengths of the growing stages may have affected the accuracy of estimated $E T_{c}$. The $K_{e}$ value was selected for silt loam soil and adjusted for surface soil wetness.

Figure 3 shows that $K_{c b}$ and single- $K_{c}$ crop curves are timeaveraged for the initial, development, mid-season and late season crop growth stages. In the initial stage, $E_{s}$ is the predominant component of $E T_{c^{\prime}}$ and $K_{c b}$ and single- $K_{c}$ are constant representing average rate of $E_{s}$ from a dry soil surface. In the crop development stage, $K_{c b}$ and single- $K_{c}$ are increasing. This is due to the development and expansion leaf surface. As the number and size of leaves increase, the number of stomata increases and so is the transpiration rate. The transpiration rate increase is directly related to $E T_{c}$. At mid-season stage, the full canopy cover is reached and transpiration rate is typically at a potential (maximum) rate. As the leaves mature and senescence set in, the number of leaves transpiring decreases and the crop curve decreases. The dual- $K_{c}$ is responsive to the 

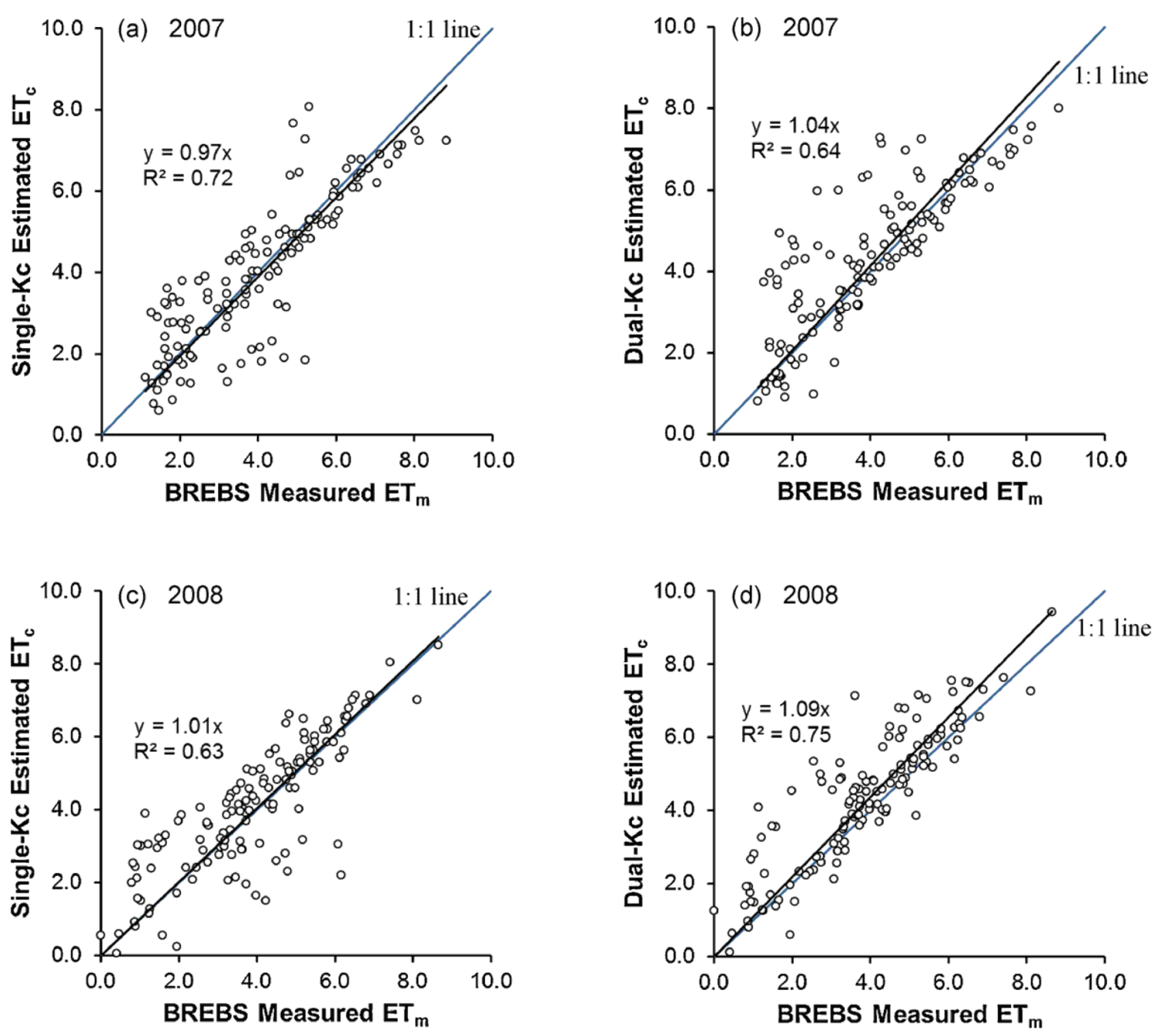

Figure 5. Regression plots of seasonal $E T_{m}$ and $E T_{c}$ estimated by the single- $K_{c}$ and dual- $K_{c}$ methods.

surface wetness and increases whenever the soil surface was moist, following rainfall especially during the initial and lateseason growth stages. Effects of surface wetness were minor after full cover was reached. For example, Figure 3 showed high peaks in dual- $K_{c}$ during the initial and crop development stages following rainfall events, while the impact of rainfall on $K_{c}$ value was less pronounced during mid-season stage.

\subsection{Estimated $E T_{c}$ with single- $K_{c}$ and dual- $K_{c}$ methods unad- justed for residue cover}

BREBS-measured $E T_{m}$ and $E T_{c}$ estimated using the single$K_{c}$ and dual- $K_{c}$ methods had similar trends and responses to changes in daily meteorological conditions throughout the growing season in both 2007 and 2008 as shown in Figure 4. However, large differences between $E T_{m}$ and $E T_{c}$ values are observed during the initial and at the end of the late-season growth stages. In both years, the single- $K$ underestimated $E T_{m}$ during the initial crop growth period while dual- $K_{c}$ overestimated $E T_{m}$ during the same growth stage. Cumulative $E T_{m}$ during the initial growth stage was $55.4 \mathrm{~mm}$ in 2007 and $66.0 \mathrm{~mm}$ in 2008. The single- $K_{c}$ method underestimated $E T_{m}$ during the initial stage by 21.1 and $33.6 \%$ in 2007 and 2008, respectively. The RMSD and MBE between $E T_{m}$ and $E T_{c}$ estimated by single- $K_{c}$ during the same stage were $1.56 \mathrm{~mm} \mathrm{~d}^{-1}$ and $0.60 \mathrm{~mm}$, respectively, in 2007; and $1.84 \mathrm{~mm} \mathrm{~d}^{-1}$ and $1.1 \mathrm{~mm}$, respectively, in 2008 . The dual $K_{c}$ method overestimated $E T_{m}$ during the initial growth stage by 16.8 and $16.5 \%$ in 2007 and 2008, respectively. The RMSD and MBE between $E T_{m}$ and $E T_{c}$ estimated by dual- $K_{c}$ during the same stage were $1.1 \mathrm{~mm} \mathrm{~d}^{-1}$ and $-0.5 \mathrm{~mm}$, respectively, in 2007; and $1.2 \mathrm{~mm} \mathrm{~d}^{-1}$ and $-0.5 \mathrm{~mm}$, respectively, in 2008. The coefficient of efficiency $(E)$ between $E T_{m}$ and the estimated $E T_{c}$ during the same stage was 0.40 for single- $K_{c}$ and 0.80 for dual- $K_{c}$ in 2007, and 0.60 for single- $K_{c}$ and 0.89 for dual- $K_{c}$ in 2008 .

During the crop development growth stage, both single- $K_{c}$ and dual- $K_{c}$ methods overestimated $E T_{m}$. Cumulative $E T_{m}$ during the development growth stage was $109 \mathrm{~mm}$ in 2007 and $123 \mathrm{~mm}$ in 2008. The single- $K_{c}$ method overestimated $E T_{m}$ during the development stage by 16.1 and $11.0 \%$ in 2007 and 2008, respectively. The RMSD and MBE between $E T_{m}$ and the single- $K_{c}$ estimated $E T_{c}$ during the same stage were $1.3 \mathrm{~mm} \mathrm{~d}^{-1}$ and $-0.6 \mathrm{~mm}$, respectively, in 2007; and $1.0 \mathrm{~mm} \mathrm{~d}^{-1}$ and $-0.4 \mathrm{~mm}$, respectively, in 2008 . The dual- $K_{c}$ method overestimated $E T_{m}$ during the development stage by 18.1 and $13.8 \%$ in 2007 and 2008, respectively. The RMSD and $M B E$ between $E T_{m}$ and dual- $K_{c}$ estimated $E T_{c}$ during the same stage were $1.3 \mathrm{~mm} \mathrm{~d}^{-1}$ and $-0.7 \mathrm{~mm}$, respectively, in 2007; and $1.0 \mathrm{~mm} \mathrm{~d}^{-1}$ and $-0.6 \mathrm{~mm}$, respectively, in 2008. Cumulative $E T_{c}$ estimated by single- $K_{c}$ and dual $-K_{c}$ methods during the development growth stage were $43.7 \mathrm{~mm}$ and $64.7 \mathrm{~mm}$, respectively, in 2007 and $43.9 \mathrm{~mm}$ and $76.9 \mathrm{~mm}$, respectively, in 2008 . The agreement between $E T_{m}$ and $E T_{c}$ was very good $(E>0.98)$ for both the single- $K_{c}$ and dual- $K_{c}$ methods during the midseason growth stage. At the mid-season stage, the plant canopy attains effective full ground cover and $E T_{c}$ is predom- 
inantly plant transpiration (T). Cumulative $E T_{m}$ during the mid-season growth stage was $313 \mathrm{~mm}$ in 2007 and $289 \mathrm{~mm}$ in 2008. The single- $K_{c}$ and dual- $K_{c}$ methods underestimated $E T_{m}$ during the mid-season growth stage by 4.2 and $4.4 \%$ in 2007 , respectively, but in 2008 both methods overestimated $E T_{m}$ by $3 \%$. The RMSD during the mid-season growth stage was low $\left(0.4 \mathrm{~mm} \mathrm{~d}^{-1}\right)$ for both single- $K_{c}$ and dual- $K_{c}$ methods in 2007 and 2008 crop growing seasons.

The agreement between $E T_{m}$ and $E T_{c}$ during the late-season growth stage was poor for both $K_{c}^{c}$ methods. Both single- $K_{c}$ and dual- $K_{c}$ overestimated $E T_{m}$ towards the end of the late-season stage. The late-season growing stage of soybean is usually marked by senescence of leaves, beginning with the lowest leaves of the plant. High temperatures may accelerate senescence and shorten the late season stage. Cumulative $E T_{m}$ during the late season growing stage was $58.4 \mathrm{~mm}$ in 2007 and $41.8 \mathrm{~mm}$ in 2008. The single- $K_{c}$ method overestimated $E T_{m}$ during the late season stage by 12.8 and $60.2 \%$ in 2007 and 2008, respectively. The RMSD and MBE between $E T_{m}$ and the single- $K_{c}$ estimated $E T_{c}$ during the same stage were $0.9 \mathrm{~mm} \mathrm{~d}^{-1}$ and $-0.3 \mathrm{~mm}$, respectively, in 2007 ; and $1.3 \mathrm{~mm} \mathrm{~d}^{-1}$ and $-1.1 \mathrm{~mm}$, respectively, in 2008 . The dual- $K_{c}$ method overestimated $E T_{m}$ during the development stage by 51 and $75 \%$ in 2007 and 2008, respectively. The RMSD and MBE between $E T_{m}$ and dual- $K_{c}$ estimated $E T_{c}$ during the same stage were $1.8 \mathrm{~mm} \mathrm{~d}^{-1}$ and $-1.3 \mathrm{~mm}$, respectively, in 2007 ; and $1.6 \mathrm{~mm} \mathrm{~d}^{-1}$ and $-1.3 \mathrm{~mm}$, respectively, in 2008 .

Figure 5 shows the regression plots of $E T_{m}$ and $E T_{c}$ estimated by the both $K_{c}$ methods for the whole crop season counted from planting to the end of the late season stage. The $R^{2}$ for the single- $K_{c}$ and dual $-K_{c}$ methods was 0.72 and 0.64 , respectively, for the 2007 crop season and 0.63 and 0.75 , respectively, for the 2008 crop season. These results show that in 2007, the $E T_{c}$ estimated by the single- $K_{c}$ method was in closer agreement to $E T_{m}$ than the $E T_{c}$ estimated by the dual $-K_{c}$ method. But in 2008, the reverse was true with the $E T_{c}$ estimated by the dual- $K_{c}$ method being in closer agreement to $E T_{m}$ indicating inconsistency of the $K_{c}$ method in estimating $E T_{c}$. Figure 6 shows the seasonal cumulative $E T_{m}$ and $E T_{c}$ in 2007 and 2008 crop seasons. The seasonal cumulative $E T_{m}$ was $535 \mathrm{~mm}$ in 2007 and $520 \mathrm{~mm}$ in 2008. The seasonal cumulative $E T_{c}$ estimated by the single- $K_{c}$ method was equal to the seasonal cumulative $E T_{m}$ in 2007 and it overestimated the seasonal cumulative $E T_{m}^{m}$ by $27.3 \mathrm{~mm}(5.3 \%)$ in 2008 . The dual- $K_{c}$ method overestimated the seasonal cumulative $E T_{m}$ by $45.6 \mathrm{~mm}(8.5 \%)$ in 2007 and by $67.9 \mathrm{~mm}(13.1 \%)$. The RMSD and $E$ between $E T_{m}$ and single- $K_{c}$ estimated $E T_{c}$ for the entire crop season were $1.0 \mathrm{~mm} \mathrm{~d}^{-1}$ and 0.92 , respectively, for 2007; and $1.1 \mathrm{~mm} \mathrm{~d}^{-1}$ and 0.90 , respectively, for 2008. Similarly, the RMSD and $E$ between $E T_{m}$ and dual- $K_{c}$ estimated $E T_{c}$ for the entire crop season were $1.1 \mathrm{~mm} \mathrm{~d}^{-1}$ and 0.91 , respectively, for 2007; and $1.0 \mathrm{~mm} \mathrm{~d}^{-1}$ and 0.92 , respectively, for 2008. A two-sample $t$-test of significance analysis of the difference between the means of BREBS measured-ET $m$ and $E T_{c}$ obtained by the crop coefficient methods is given in Table 1 . The results showed no statistical significance difference between the seasonal mean of BREBS-measured $E T_{m}$ and seasonal mean of single- $K_{c}$ estimated $E T_{c}$ for both 2007 and 2008. The seasonal mean of dual- $K_{c}$ estimated $E T_{c}$ was significantly different from BREBS-measured $E T_{m}$ in 2008 but not in 2007. Comparison between the seasonal means of $E T_{c}$ estimated by the single- $K_{c}$ and dual- $K_{c}$ methods also showed statistical significance difference in 2008 but not in 2007.

\subsection{Adjustment of estimated $E T_{c}$ for surface residue cover}

In the studies cited above, $E_{\mathrm{s}}$ is shown to be reduced by surface residue cover and the proportion by which it is reduced is influenced by several factors, including residue thickness and the fraction of the soil surface covered. The FAO-56
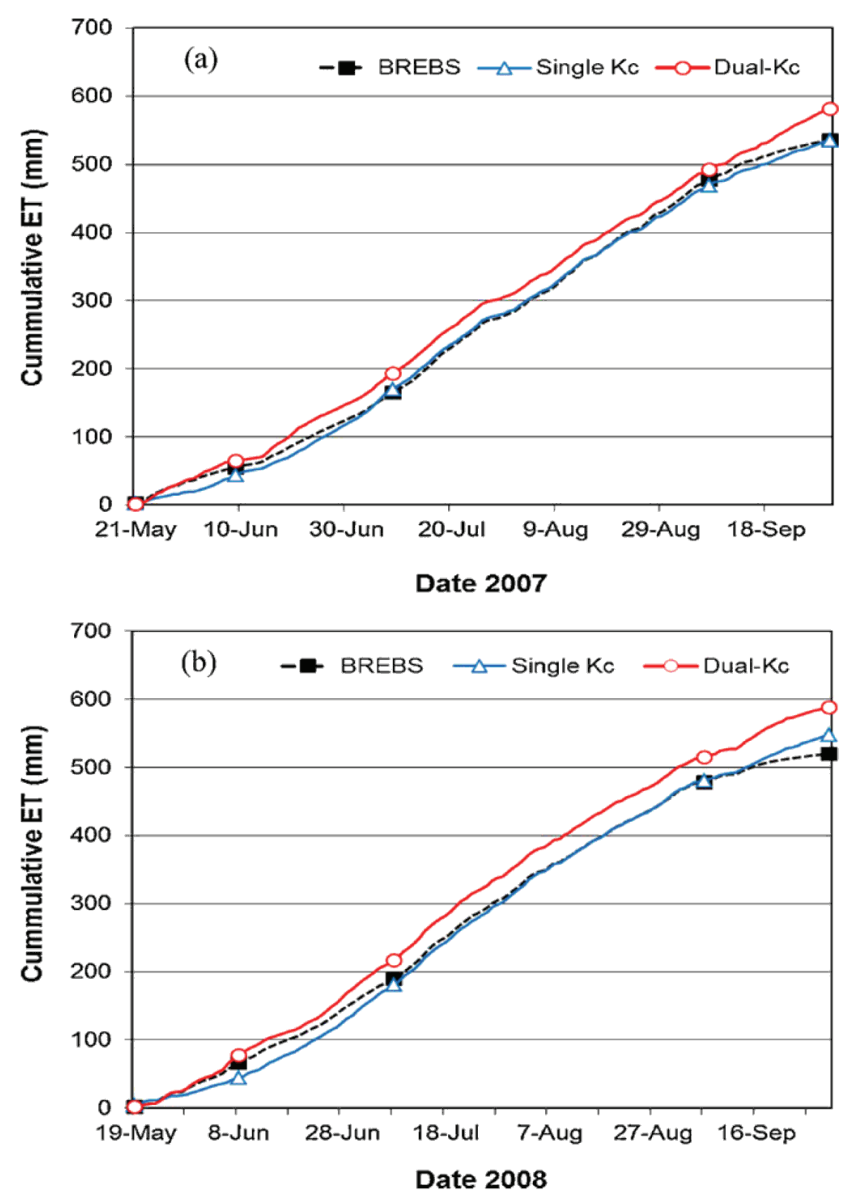

Figure 6. Cumulative ET measured by BREBS and estimated by the single- $K_{c}$ and dual- $K_{c}$ methods.

recommends a reduction of $5 \%$ in $E_{s}$ for each $10 \%$ of the soil surface covered with crop residue. However, the recommended values are only approximate and a more accurate assessment of the impact of residue is needed for precise estimation of $E T_{c}$ in cropping systems with soil surface residue cover. From the results presented in Figure 4, it was observed that single- $K_{c}$ method substantially underestimated $E T_{c}$ during the initial growing stage when $E T_{c}$ is predominantly $E_{s}$ and largely influenced by soil surface conditions. Hence, the single- $K_{c}$ method-estimated $E T_{c}$ did not need a downward adjustment on $E_{s}$ due to the impact of surface residue cover. The dual- $K_{c}$ method, on the other hand, substantially overestimated $E T_{c}$ during the initial and crop development stages and therefore needed a downward adjustment on $E_{s}$ due to the impact of surface residue cover. The $E_{s}$ component of $E T_{c}$ estimated using the dual- $K_{c}$ method was test-adjusted at four levels to determine the optimum percentage of reduction in $E_{s}$ to account for soil surface covered with crop residue. The testing levels were set at $0,2.5,5$, and $7.5 \%$ reduction in $E_{s}$ for each $10 \%$ of surface covered by residue. The estimated surface residue cover showed that in 2007 the fraction of residue cover decreased from about $86 \%$ in the early season to about $58 \%$ at the end of the season, whereas in 2008 it decreased from about $60 \%$ in the early season to $27 \%$ at the end of the season.

The regression analysis between $E T_{m}$ and the adjusted $E T_{c}$ are shown in Figures $7 \& 8$ for 2007 and 2008. Table 2 presents a summary of statistical analysis used to compare the dual$K_{c}$ estimated seasonal $E T_{c}$ at various levels of $E_{s}$ adjustment with the single- $K_{c}$ estimated $E T_{c}$ and $E T_{m}$. The best estimates of seasonal $E T_{c}$ were obtained by reducing $E_{s}$ by $5 \%$ in 2007 $\left(R^{2}=0.77, R M S D=0.87 \mathrm{~mm} \mathrm{~d}^{-1}, E=0.94\right)$ and $2008\left(R^{2}=0.83\right.$, 

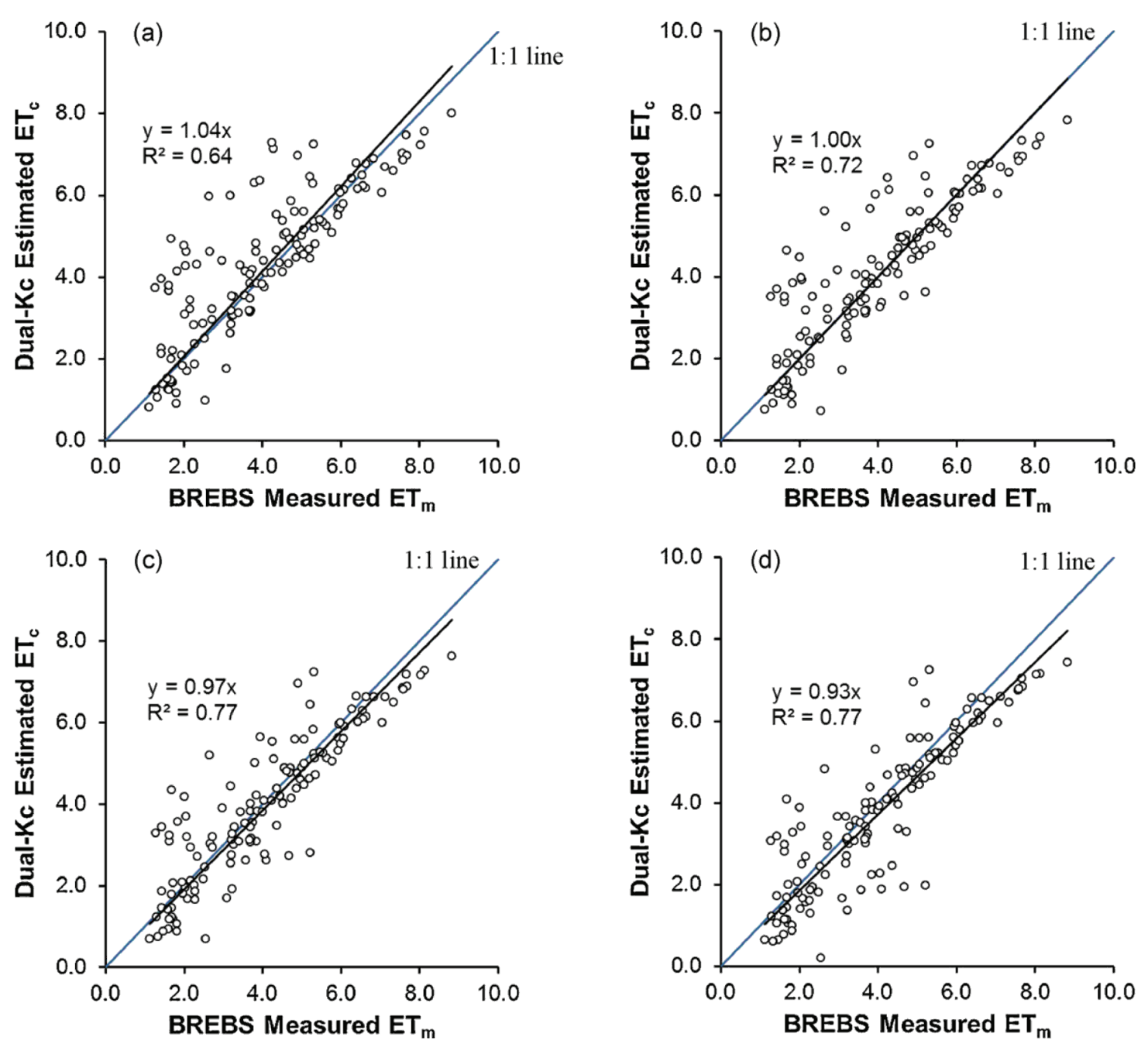

Figure 7. Regression plots of seasonal $E T_{m}$ and $E T_{c}$ estimated by the dual- $K_{c}$ methods at various levels of $E_{s}$ reduction in 2007 crop season (a) $0 \%$, (b) $2.5 \%$, (c) $5 \%$, and (d) $7.5 \%$.

$\left.R M S D=0.84 \mathrm{~mm} \mathrm{~d}^{-1}, E=0.95\right)$. Figure 9 show the cumulative $E T_{\text {by various }} E_{s}$ reduction levels compared to $E T_{m}$ and Table 3 shows the percent change in cumulative $E T$ for each growth stage at various levels of $E_{s}$ reduction per $10 \%$ of the soil sur- face covered with crop residue. The most notable changes in $E T_{c}$ due to adjustments in $E_{s}$ occur during the initial and crop development stages. During the mid-season growth stage, adjustment of $E_{s}$ due to percent of soil surface covered with

Table 1. A two-sample $t$-test of significance analysis of the difference between the means of BREBS measured-ET $m$ and $E T_{c}$ obtained by crop coefficient methods.

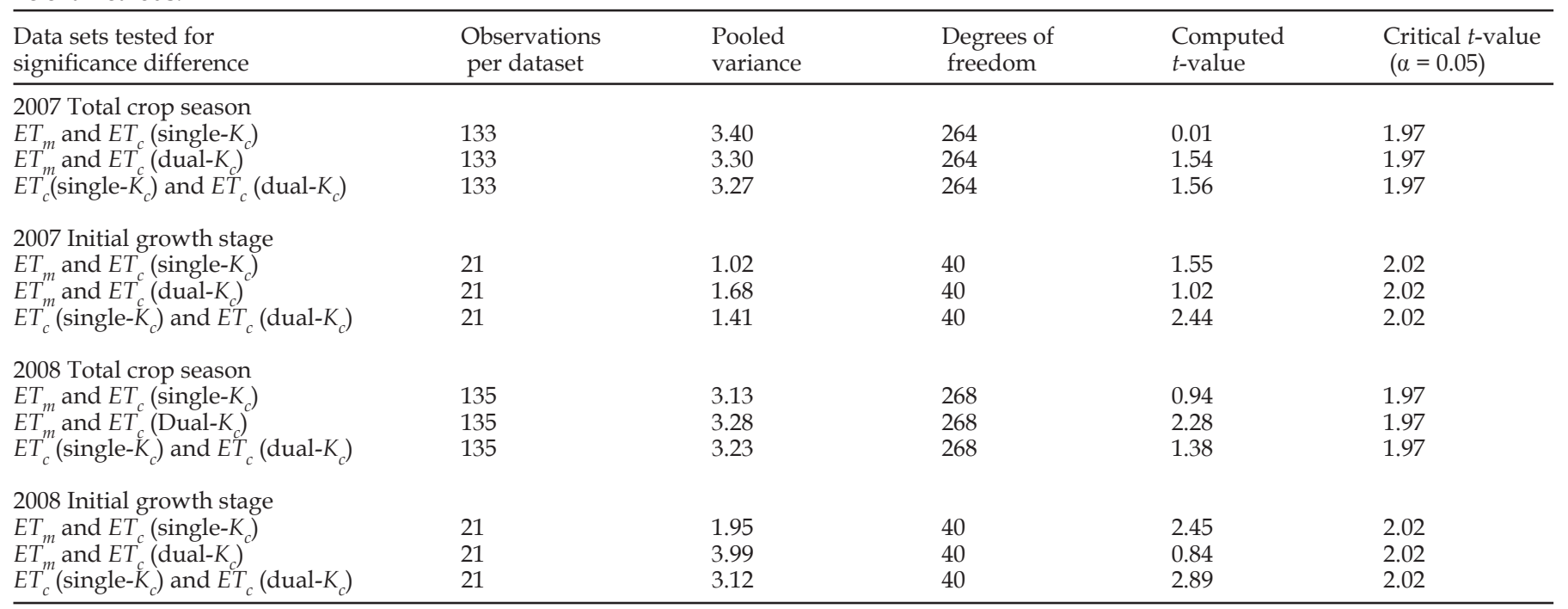



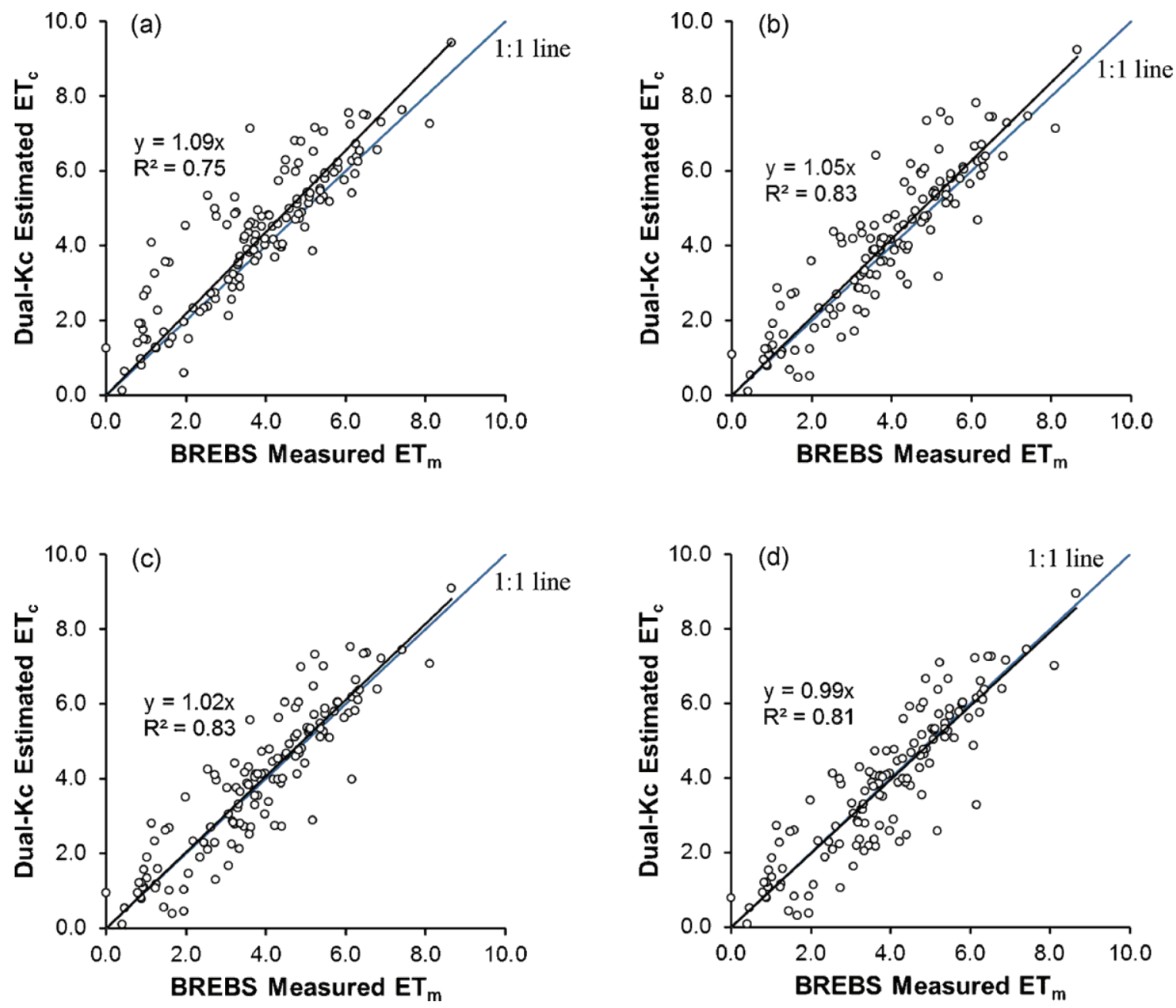

Figure 8. Regression plots of seasonal $E T_{m}$ and $E T_{c}$ estimated by the dual- $K_{c}$ methods at various levels of $E_{s}$ reduction in 2008 crop season (a) $0 \%$, (b) $2.5 \%$, (c) $5 \%$, and (d) $7.5 \%$.

crop residue had a very small impact on the estimated $E T_{c}$. The model performance during the late season growth stage was poor compared to other growth stages. The data in Table 3 show that greater improvement in $E T_{c}$ estimates can be obtained for both years by splitting the reduction of $E_{s}$ due to residue cover into two periods as follows: reducing $E_{s}^{s}$ by $2.5 \%$ for each $10 \%$ of the soil surface covered with crop residue during the initial growth stage and by $5 \%$ for each $10 \%$ of the soil surface covered with crop residue during the crop development and mid-season growth stages. The split reduction in $E_{s}$ by the above percentages resulted in $E T_{c}$ underestimation by only $3 \%$ during the initial stage and overestimation by $5 \%$ during the development stage. Reduction of $E_{s}$ by $7.5 \%$ resulted in large underestimations of $E T$ during the initial stage (42\% in 2007 and $31 \%$ in 2008). The overall results indicated that inaccurate selection of percentage reduction in $E_{s}$ can result in substantial overestimation or underestimation of seasonal $E T$ by using the dual- $K_{c}$ method. The analysis of variance of the means of

Table 2. Summary of statistical analysis used to compare the dual- $K_{c}$ estimated seasonal $E T_{c}$ at various levels of $E_{s}$ adjustment with BREBS-measured $E T_{m}$ and single- $K_{c}$ estimated $E T_{c}$.

\begin{tabular}{|c|c|c|c|c|c|c|c|c|}
\hline & $\begin{array}{l}\text { Total } \\
(\mathrm{mm})\end{array}$ & $\begin{array}{l}\text { Mean } \\
\left(\mathrm{mm} \mathrm{d}^{-1}\right)\end{array}$ & $\begin{array}{l}\operatorname{Max} \\
\left(\mathrm{mm} \mathrm{d}^{-1}\right)\end{array}$ & $\begin{array}{l}\text { Min } \\
\left(\mathrm{mm} \mathrm{d}^{-1}\right)\end{array}$ & $\begin{array}{l}\text { RMSD } \\
\left(\mathrm{mm} \mathrm{d}^{-1}\right)\end{array}$ & $\begin{array}{l}M B E \\
(\mathrm{~mm})\end{array}$ & $R^{2}$ & E \\
\hline \multicolumn{9}{|l|}{2007} \\
\hline BREBS & 535.4 & 4.0 & 8.8 & 1.1 & & & & \\
\hline Dual- $K^{c}\left(2.5 \% E_{\text {s }}\right.$ reduction $)$ & 555.3 & 4.2 & 7.8 & 0.7 & 0.932 & -0.150 & 0.72 & 0.930 \\
\hline Dual- $K_{c}^{c}\left(5 \% E_{s}\right.$ reduction) & 529.6 & 4.0 & 7.6 & 0.7 & 0.873 & 0.043 & 0.77 & 0.940 \\
\hline Dual $-K^{c}\left(7.5 \%{ }^{s} E_{c}\right.$ reduction $)$ & 503.8 & 3.8 & 7.4 & 0.2 & 0.939 & 0.236 & 0.77 & 0.932 \\
\hline Single- $K_{c}$ & 535.0 & 4.0 & 8.1 & 0.6 & 0.975 & 0.002 & 0.72 & 0.926 \\
\hline BREBS & 520.0 & 3.9 & 8.7 & 0.4 & & & & \\
\hline Dual- $K_{c}\left(0 \% E_{\mathrm{s}}\right.$ reduction $)$ & 587.9 & 4.4 & 9.4 & 0.1 & 0.997 & -0.503 & 0.75 & 0.923 \\
\hline Dual- $K^{c}\left(2.5 \%{ }^{s} E_{c}\right.$ reduction $)$ & 549.0 & 4.1 & 9.2 & 0.1 & 0.838 & -0.214 & 0.83 & 0.948 \\
\hline Dual- $K_{c}^{c}$ (5\% $E_{\varsigma}$ reduction) & 532.2 & 3.9 & 9.1 & 0.1 & 0.810 & -0.091 & 0.83 & 0.951 \\
\hline Dual- $K_{c}^{c}\left(7.5 \%{ }^{s} E_{s}\right.$ reduction $)$ & 515.5 & 3.8 & 9.0 & 0.1 & 0.858 & 0.033 & 0.81 & 0.946 \\
\hline Single- $K_{c}$ & 547.3 & 4.1 & 8.5 & 0.1 & 1.063 & -0.203 & 0.63 & 0.904 \\
\hline
\end{tabular}



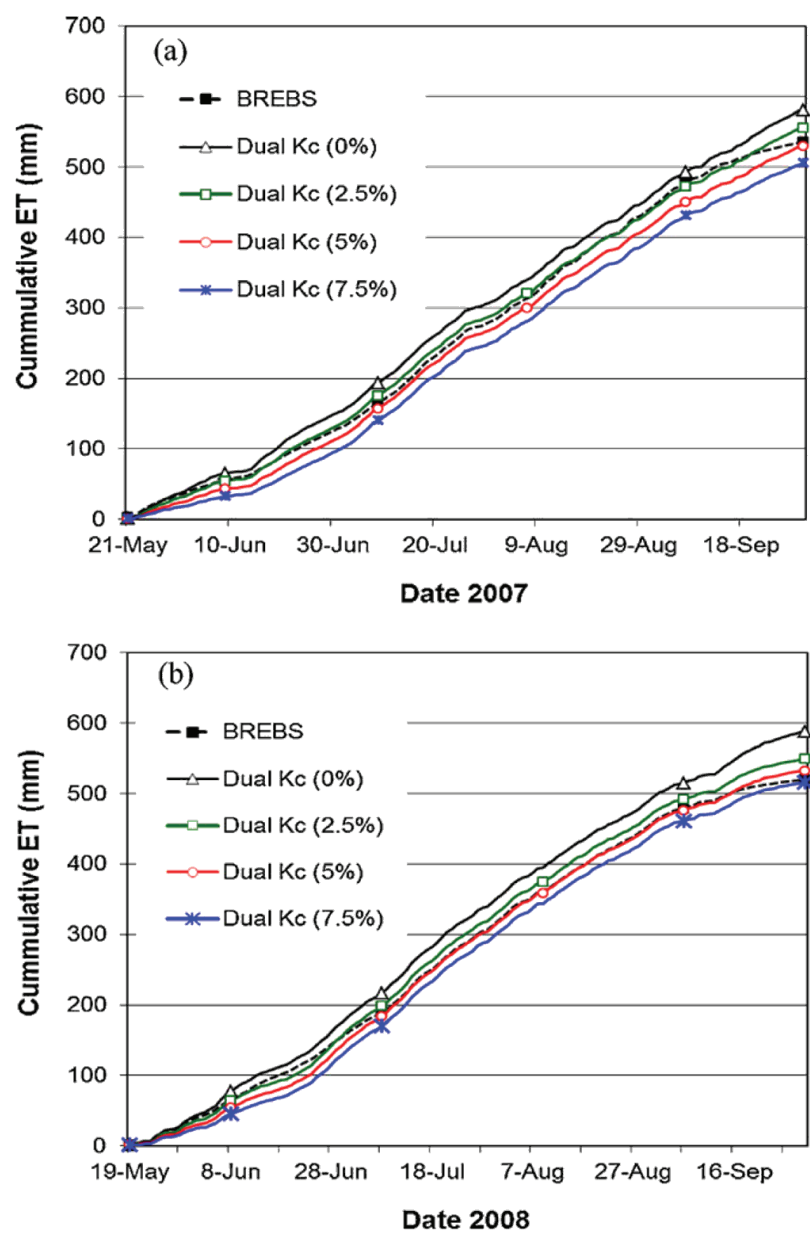

Figure 9. Cumulative ET measured by BREBS and estimated by the dual- $K_{c}$ method at $0 \%, 2.5 \%, 5 \%$, and $7.5 \%$ reductions in $E_{s}$ (a) 2007 and $(b)^{c} 2008$.

estimated $E T_{c}$ obtained by the dual- $K_{c}$ method at $0,2.5,5$ and $7.5 \%$ reductions in $E_{s}$ for each $10 \%$ of soil surface covered with crop residue are given in Table 4 . The results indicate that the differences between $E T_{c}$ obtained at various levels of $E_{s}$ reduction were not significantly different except for the period during the initial growth stage in 2007.
Table 3. Percent overestimation or underestimation in $E T$ estimated by the dual- $K_{c}$ at various levels of reduction in $E_{s}$ for each $10 \%$ of soil surface covered with crop residue as compared to BREBS-measured $E T_{m}$.

Crop growth stage Percent reduction in $E_{s}$ for each $10 \%$ of soil surface covered with crop residue

\begin{tabular}{lllll} 
& $0 \%$ & $2.5 \%$ & $5.0 \%$ & $7.5 \%$ \\
\hline 2007 & +16.6 & -3.2 & -23.1 & -41.8 \\
Initial & +18.2 & +11.7 & +5.1 & -1.4 \\
Crop development & -4.2 & -5.2 & -6.2 & -7.1 \\
Mid-season & +51.0 & +43.2 & +136.0 & +27.4 \\
Late-season & +8.5 & +3.7 & -1.1 & -5.8 \\
Total crop season & & & & \\
2008 & +16.5 & -3.0 & -17.3 & -31.4 \\
Initial & +13.7 & +8.6 & +4.9 & +1.1 \\
Crop development & +3.0 & +1.6 & +1.1 & +0.6 \\
Mid-season & +75.4 & +37.6 & +34.7 & +31.6 \\
Late-season & +13.1 & +5.6 & +2.3 & -0.9 \\
Total crop season & & & & \\
\hline
\end{tabular}

\section{Summary and conclusions}

This study compared the accuracy of the single- $K_{c}$ and dual- $K_{c}$ methods for estimation of daily $E T_{c}$ in a cropping system with soil surface residue cover and determined the magnitude by which $E T_{c}$ is reduced for each $10 \%$ of soil surface covered with crop residue. The $E T_{\text {c }}$ estimates from the two methods were compared to the BREBS-measured $E T_{m}$. The results indicate that the single- $K_{c}$ underestimated $E T_{m}^{m}$ during the initial crop growth stage by $21.1 \%$ in 2007 and $33.6 \%$ in 2008 while the dual- $K_{c}$ unadjusted for residue cover overestimated $E T_{m}$ during the same growth stage by $16.8 \%$ in 2007 and $16.5 \%$ in 2008. Both single- $K_{c}$ and unadjusted dual$K_{c}$ methods overestimated $E T_{m}$ during the crop development stage at about the same level. The single- $K_{c}$ method overestimated $E T_{m}$ during the development stage by 16.1 and $11.0 \%$ in 2007 and 2008, respectively, and the unadjusted dual- $K$ method overestimated $E T_{m}$ during the same stage by 18.1 and $13.8 \%$ in 2007 and 2008, respectively. Both methods accurately estimated $E T_{m}$ during the mid-season stage and there was no difference between them. The single- $K_{c}$ and unadjusted dual- $K_{c}$ methods underestimated $E T_{m}$ during the mid-season growth stage by 4.2 and $4.4 \%$ in 2007, respectively, but in 2008 both methods overestimated $E T_{m}$ by $3 \%$. There was, however, poor agreement between $E T_{c}$ estimated by both methods and

Table 4. Analysis of variance to test the hypothesis that the mean of estimated $E T_{c}$ values obtained by dual- $K_{c}$ methods at $0,2.5,5$ and $7.5 \%$ reduction in $E_{s}$ for each $10 \%$ of soil surface covered with crop residue are the same.

\begin{tabular}{|c|c|c|c|c|c|}
\hline Source of variation & $\begin{array}{l}\text { Sum of } \\
\text { squares }\end{array}$ & $\begin{array}{l}\text { Degrees of } \\
\text { freedom }\end{array}$ & $\begin{array}{l}\text { Mean } \\
\text { square }\end{array}$ & $\begin{array}{l}\text { Computed } \\
\text { F-value }\end{array}$ & $\begin{array}{l}\text { Critical } F \text {-value } \\
(\alpha=0.05)\end{array}$ \\
\hline $\begin{array}{l}2007 \text { Whole crop season: } \\
\text { Between levels of } E_{s} \text { reduction } \\
\text { Within data set } \\
\text { Total }\end{array}$ & $\begin{array}{l}24.85 \\
1708.98 \\
1733.82\end{array}$ & $\begin{array}{l}3 \\
528 \\
531\end{array}$ & $\begin{array}{l}8.28 \\
3.24\end{array}$ & 2.56 & 2.62 \\
\hline $\begin{array}{l}2007 \text { Initial growth stage: } \\
\text { Between levels of } E_{s} \text { reduction } \\
\text { Within data set } \\
\text { Total }\end{array}$ & $\begin{array}{l}29.07 \\
90.60 \\
119.66\end{array}$ & $\begin{array}{l}3 \\
80 \\
83\end{array}$ & $\begin{array}{l}9.69 \\
1.13\end{array}$ & 8.56 & 2.72 \\
\hline $\begin{array}{l}2008 \text { Whole crop season: } \\
\text { Between levels of } E_{s} \text { reduction } \\
\text { Within data set } \\
\text { Total }\end{array}$ & $\begin{array}{l}21.42 \\
1971.79 \\
1993.21\end{array}$ & $\begin{array}{l}3 \\
536 \\
539\end{array}$ & $\begin{array}{l}7.14 \\
3.68\end{array}$ & 1.94 & 2.62 \\
\hline $\begin{array}{l}2008 \text { Initial growth stage: } \\
\text { Between levels of } E_{s} \text { reduction } \\
\text { Within data set } \\
\text { Total }\end{array}$ & $\begin{array}{l}25.97 \\
305.12 \\
331.09\end{array}$ & $\begin{array}{l}3 \\
80 \\
83\end{array}$ & $\begin{array}{l}8.66 \\
3.81\end{array}$ & 2.27 & 2.72 \\
\hline
\end{tabular}


the $E T_{m}$ towards the end of the late season stage showing that both methods had poor performance in estimating initial and late season stage $E T_{c}$. There was no statistical significant difference between the seasonal mean of BREBS-measured $E T_{m}$ and the seasonal mean of single- $K_{c}$ estimated $E T_{c}$ for both 2007 and 2008. The seasonal mean of dual- $K_{c}$ estimated $E T_{c}$ was significantly different from the BREBS-measured $E T_{m}$ in 2008 but not in 2007. Comparison between the seasonal means of $E T$ estimated by the single- $K_{c}$ and dual- $K_{c}$ methods also showed statistical significant difference in 2008 but not in 2007.

Downward adjustments in $E_{s}$ for every $10 \%$ of the soil surface covered with crop residue improved the performance of the dual- $K_{c}$ method. The $E_{s}$ component of $E T_{c}$ estimated using the dual- $K_{c}$ method was test-adjusted at four levels to determine the percentage reduction for each $10 \%$ surface cover that best represents the field conditions. The testing levels were set at $0,2.5,5$, and $7.5 \%$ reduction in $E_{s}$ for each $10 \%$ of surface covered by the residue. The most notable changes in $E T_{c}$ due to adjustments in $E_{s}$ occur during the initial growing stage. The best results were obtained by reducing $E_{s}$ by $5 \%$ for every $10 \%$ of surface covered with residue in 2007 $\left(R^{2}=0.77, R M S D=0.87 \mathrm{~mm} \mathrm{~d}^{-1}, E=0.94\right)$ and $2008\left(R^{2}=0.83\right.$, $\left.R M S D=0.84 \mathrm{~mm} \mathrm{~d}^{-1}, E=0.95\right)$. In terms of cumulative $E T_{c^{\prime}}$ the dual- $K_{c}$ adjusted at $2.5 \%$ reduction in $E_{s}$ for each $10 \%$ of soil surface covered with crop residue gave best results for the initial stage and adjustment at $5 \%$ reduction in $E_{\mathrm{s}}$ gave best results for the crop development and mid-season growth stages. The $t$-test of significance difference also showed that the differences in means of $E T_{c}$ obtained at various levels of $E_{s}$ reduction were not significantly different except for the period during the initial growth stage in 2007. The differences in percent reduction in $E_{s}$ between the two years may be due to the fact that residue cover in 2007 was predominantly from a previous year maize crop and residue cover in 2008 was predominantly from the soybean harvested at the end of the 2007 crop season. These results indicated that inaccurate selection of percentage reduction in $E_{s}$ can result in substantial overestimation or underestimation of seasonal $E T_{c}$ by the dual $-K_{c}$ method. Results also emphasize that the single and dual $K_{c}^{c}$-values are influenced differently by the same management practice (i.e., tillage, residue). Given the tremendous amount of variability in soil and crop management, climate conditions, irrigation method and irrigation regime practiced, and many other factors, the $K_{c}$-values reported in the literature, including the FAO-56 values, should be adjusted for local management conditions for more accurate $E T_{c}$ estimates.

\section{References}

Aber, J.D., Melillo, J.M., 1982. Nitrogen immobilization in decaying hardwood leaf litter as a function of initial nitrogen and lignin content. Can. J. Bot. 60, 2263-2269.

Adams, J.E., 1966. Influence of mulches on runoff, erosion, and soil moisture depletion. SSSA Proc. 30, 110-114.

Amatya, D.M., Skaggs, R.W., Gregory, J.D., 1995. Comparison of methods for estimating reference ET. J. Irrig. Drain. Eng. 121, 427-435.

ASCE-EWRI. 2005. The ASCE standardized reference evapotranspiration equation. Report of the Task Committee on Standardization of Reference Evapotranspiration.

Am. Soc. Civil Engineers-Environmental and Water Resources Institute, Reston, VA.

Bond, J.J., Willis, W.O., 1970. Soil water evaporation: first stage drying as influenced by surface residue and evaporation potential. SSSA Proc. 34, 110-114.

Bowen, I.S., 1926. The ratio of heat losses by conduction and evaporation from any water surface. Phys. Rev. 27, 779-787.

Chung, S.O., Horton, R., 1987. Soil heat and water flow with a partial surface mulch. Water Resour. Res. 23, 2175-2186.
Choudhury, B.J., Monteith, J.L., 1988. A four-layer model for the heat budget of homogeneous land surfaces. Q. J. R. Meteorol. Soc. 114, 373-398.

Doorenbos, J., Kassam, A.H., Bentvelsen, C.L.M., Branscheid, V. Plusje, J.M.G.A., Smith, M., Uittenbogaard. G.O., 1986. Yield response to water. FAO Irrigation and Drainage Paper No. 33, FAO, Rome, Italy.

Doorenbos, J., Pruitt, W.O., 1977. Crop water requirements: Guidelines for prediction of crop water requirements. FAO Irrig. and Drain. Paper No. 24 (rev.), FAO Rome, Italy.

FAO-56. 1998. Crop evapotranspiration: Guidelines for computing crop water requirements. Irrigation and Drainage Paper No. 56. Food and Agriculture Organization of the United Nations, Rome, Italy.

Flury, M., Mathison, J.B., Wu, J.Q., Schillinger, W.F., Stockle, C.O., 2009. Water vapor diffusion through wheat straw residue. SSSA J. 73, 37-45.

Gardiol, J.M., Serio, L.A., Maggiora, A.I.D., 2003. Modelling evapotranspiration of corn (Zea mays) under different plant densities. J. Hydrol. 271, 188-196.

Guan, H., Wilson, J.L., 2009. A hybrid dual source model for potential evapotranspiration partitioning. J. Hydrol. 377, 405-416.

Gregory, J.M., 1982. Soil cover prediction with various amounts and types of crop residue. Trans. ASAE 25, 1333-1337.

Gregory, J.M., McCarty, T.R., Ghidey, F., Alberts, E.E., 1985. Derivation and evaluation of residue decay equation. Trans. ASAE 28, 98-101.

Hatfield, J.L., 1990. Methods of estimating evapotranspiration. In: Stewart, B.A., Nielsen, D.R. (Eds.), Irrigation of Agricultural Crops. Agron. Monogr. 30. ASA, CSSA and SSSA, Madison, WI, pp. 435-474.

Hammel, J.E., 1996. Water conservation practices for sustainable dryland farming systems in the Pacific Northwest. Am. J. Altern. Agric. 11, 58-63.

Heilman, J.L., McInnes, K.J., Gesch, R.W., Lascano, R.J., 1992. Evaporation from ridge-tilled soil covered with herbicide-killed winter wheat. SSSA J. 56, 1278-1286.

Irmak, S., Istanbulluoglu, E., Irmak, A., 2008. An evaluation of evapotranspiration model complexity against performance in comparison with Bowen ratio energy balance measurements. Trans. ASABE 51, 1295-1310.

Irmak, S., Mutiibwa, D., 2009a. On the dynamics of stomatal resistance: relationships between stomatal behavior and micrometeorological variables and performance of Jarvis-type parameterization. Trans. ASABE 52, 1923-1939.

Irmak, S., Mutiibwa, D., 2009b. On the dynamics of evaporative losses from Penman-Monteith with fixed and variable canopy resistance during partial and complete canopy. Trans. ASABE 52, 1139-1153.

Irmak, S., 2010. Nebraska water and energy flux measurement, modeling, and research network (NEBFLUX). Trans. ASABE 53, 1097-1115.

Jensen, M.E., Robb, D.C.N., Franzoy, C.E., 1970. Scheduling irrigation using climate-crop-soil data. J. Irrig. Drain. Div. 96, 25-38.

Jensen, M.E., Wright, J.L., Pratt, B.J., 1971. Estimating soil moisture depletion from climate, crop, and soil data. Trans. ASABE 14, 954-959.

Klocke, N.L., Currie, R.S., Aiken, R.M., 2009. Soil water evaporation and crop residues. Trans. ASABE 52, 103-110.

Kustas, W.P., Norman, J.M., 1999. Evaluation of soil and vegetation heat flux prediction using a simple two-source model with radiometric temperatures for partial canopy cover. Agric. For. Meteorol. 94, 13-29.

Lagos, L.O., Martin, D.L., Verma, S.B., Suyker, A., Irmak, S., 2009. Surface energy balance model of transpiration from variable canopy cover and evaporation from residue-covered or bare-soil systems. Irrig. Sci. 28, 51-64.

Legates, D.R., McCabe Jr., G.J., 1999. Evaluating the use of "goodness of fit" measures in hydrologic and hydroclimatic model validation. Water Resour. Res. 35 (1), 233-241.

Lopez-Urrea, R., Olalla, F.M., Fabeiro, C., Moratalla, A., 2006. An evaluation of two hourly reference evapotranspiration equations for semiarid conditions. Agric. Water Manage. 86 (3), 277-282. 
Lui, Y., Pereira, L.S., 2000. Validation of FAO methods for estimating crop coefficients. Trans. CSAE 16 (5), 26-30.

Majnooni-Heris, A., Zand-Parsa, S.H., Sepaskhah, A.R., KamgarHaghighi, A.A., 2007. Comparison of MSM Model for Prediction of Potential Evapotranspiration of Maize with FAO Methods JWSS - Isfahan University of Technology, Iran. 11(41), pp. 29-42.

Meentemeyer, V., 1978. Macroclimate and lignin control of litter decomposition rates. Ecology 59, 465-472.

Monteith, J.L., 1965. Evaporation and the environment. Proc. Symp. Soc. Exp. Biol. 19, 205-234.

Moody, J.E., Jones Jr., J.N., Lillard, J.H., 1963. Influence of straw mulch on soil moisture, soil temperature, and the growth of corn. SSSA Proc. 27, 700-703.

Mutiibwa, D., Irmak, S., 2011. On the scaling up soybean leaf level stomatal resistance to canopy resistance for one-step estimation of actual evapotranspiration. Trans. ASABE 54 (1), 141-154.

Nice, R.G., Buehring, N.W., Shaw, D.R., 2001. Sicklepod (Senna obtusifolia) response to shadding, soybean (Glycine max) row spacing, and population in three management systems. Weed Technol. 15, 155-162.

Norman, J.M., Kustas, W.P., Humes, K.S., 1995. A two-source approach for estimating soil and vegetation energy fluxes from observations of directional radiometric surface temperature. Agric. For. Meteorol. 77, 263-293.

Parr, J.F., Papendick, R.I., 1978. Factors affecting decomposition of crop residues by micro-organisms. In: Oschwald, W.R. (Ed.), Crop Residue Management Systems. ASA, CSSA and SSSA, Madison, WI, pp. 101-129, Special Publ. 3.

Pereira, L.S., Perrier, A., Allen, R.G., Alves, I., 1996. Evapotranspiration: Review of concepts and future trends. In: Camp, C.R., Sadler, E.J., Yoder, R.E. (Eds.), Evapotranspiration and Irrigation Scheduling. Proc. of the International Conf. November 2-6, San Antonio, TX, pp. 109-115.

Quemada, M., 2004. Predicting crop residue decomposition using moisture adjusted time scales. Nutr. Cycl. Agroecosyst. 70, 283-291.

Raes, D., Steduto, P., Hsiao, T.C., Fereres, E., 2009. Aquacrop Reference Manual. FAO, Land and Water Division, Rome, Italy.

Reinertsen, S.A., Elliot, L.F., Cochran, V.L., Campbell, G.S., 1984. Role of available carbon and nitrogen in determining the rate of wheat straw decomposition. Soil Biol. Biochem. 16, 459-464.

Renner, K.A., Mickelson, J.A., 1997. Weed control using reduced rates of postemergence herbicides in narrow and wide row soybean. J. Prod. Agric. 10, 431-437.

Roper, M.M., 1985. Straw decomposition and nitrogenase activity $\left(\mathrm{C}_{2} \mathrm{H}_{2}\right.$ reduction): effects of soil moisture and temperature. Soil Biol. Biochem. 17, 65-71.

Rosadi, R.A., Afandi, B., Senge, M., Ito, K., Adomako, J.T., 2007. The effect of water deficit in typical soil types on the yield and water requirement of soybean (Glycine max [L.] Merr.) in Indonesia. Japan Agric. Res. Q. 41, 47-52.

Russel, J.C., 1939. The effect of surface cover on soil moisture losses by evaporation. SSSA Proc. 4, 65-70.

Shelton, D.P., Smith, J., Jasa, P.J., 2000. Estimating residue cover. In: Conservation Tillage Systems and Management, 2nd ed, MWPS45 , pp. 35-46.
ShiZhang, P., JiaLi, D., Zhi, M., JunZheng, X., DaoXi, L., 2007. Estimation and verification of crop coefficient for water saving irrigation of late rice using the FAO-56 method. Trans. CSAE 23 (7), 30-34.

Shuttleworth, W.J., Gurney, R., 1990. The theoretical relationship between foliage temperature and canopy resistance in sparse crops. Q. J. R. Meteorol. Soc. 116, 497-519.

Shuttleworth, W.J., Wallace, J.S., 1985. Evaporation from sparse cropsan energy combination theory. Q. J. R. Meteorol. Soc. 111, 839-855.

Steiner, J.N., 1989. Tillage and surface residue effects on evaporation from soils. Soil Sci. Soc. Am. J. 53 (4), 911-916.

Steiner, J.L., Schomberg, H.H., Dauglas Jr., C.L., Black, A.L., 1994. Standing stem persistence in no-tillage small-grain fields. Agron. J. 86, 76-81.

Steiner, J.L., Schomberg, H.H., Unger, P.W., Cresap, J.L., 1999. Crop residue decomposition in no-tillage small grain fields. Soil Sci. Soc. Am. J. 63, 1817-1824.

Tanner, C.B., 1960. Energy balance approach to evapotranspiration from crops. Soil Sci. Soc. Am. Proc. 24, 1-9.

Temesgen, B., Eching, S., Davidoff, B., Frame, K., 2005. Comparison of some reference evapotranspiration equations for California. J. Irrig. Drain. Eng. 131 (1), 73-84.

Todd, R.W., Klocke, N.L., Hergert, G.W., Parkhurst, A.M., 1991. Evaporation from soil influenced by crop shading, crop residue, and wetting regime. Trans. ASAE 34 (2), 461-466.

Tolk, J.A., Howell, T.A., 2001. Measured and simulated evapotranspiration of grain sorghum with full and limited irrigation in three high plain soils. Trans. ASAE 44 (6), 1553-1558.

Unger, P.W., Parker, J.J., 1976. Evaporation reduction from soil with wheat, sorghum, and cotton residues. SSSA J. 40 (6), 938-942.

van Donk, S.J., Merrill, S.D., Tanaka, D.L., Krupinsky, J.M., 2008. Crop residue in North Dakota: measured and simulated by the wind erosion prediction system. Trans. ASABE 51, 1623-1632.

van Wijk, W.R., de Vries, D.A., 1954. Evapotranspiration. Neth. J. Agric. Sci. 2, 105-119.

Ventura, F., Spano, D., Duce, P., Snyder, R.L., 1999. An evaluation of common evapotranspiration equations. Irrig. Sci. 18, 163-170.

Willis, W.O., 1962. Effect of partial surface covers on evaporation from soil. SSSA Proc. 26 (6), 598-601.

Wortmann, C.S., Klein, R.N., Wilhelm, W.W., Shapiro, C., 2008. Harvesting crop residues. NebGuide G1846. University of NebraskaLincoln Extension, IANR.

Wright, J.L., December 1981. Crop coefficients for estimates of daily crop evapotranspiration. In: Irrigation Scheduling for Water and conservation in the 80s. ASAE.

Wright, J.L., 1982. New evapotranspiration crop coefficients. J. Irrig. Drain. Eng. 108 (1), 57-74.

Wright, J.L., Jensen, M.E., 1978. Development and evaluation of evapotranspiration models for irrigation scheduling. Trans. ASAE $21(1), 88-96$

Yoder, R.E., Odhiambo, L.O., Wright, W.C., 2005. Evaluation of methods for estimating daily reference crop evapotranspiration at a site in the humid southeast of USA. Appl. Eng. Agric. 21 (2), 197-202. 